\title{
معايير تقييم جودة البحوث النوعية في العلوم الإنسانية
}

\author{
محمد بن عبد الله بن عطية الزهر اني

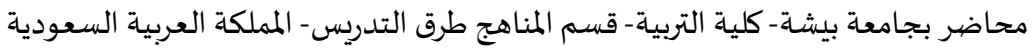

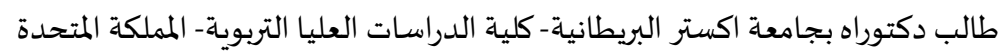 \\ alahmadim2010@gmail.com
}

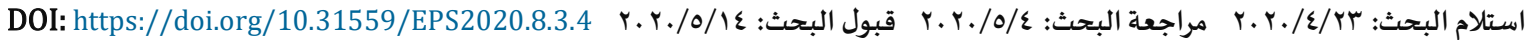

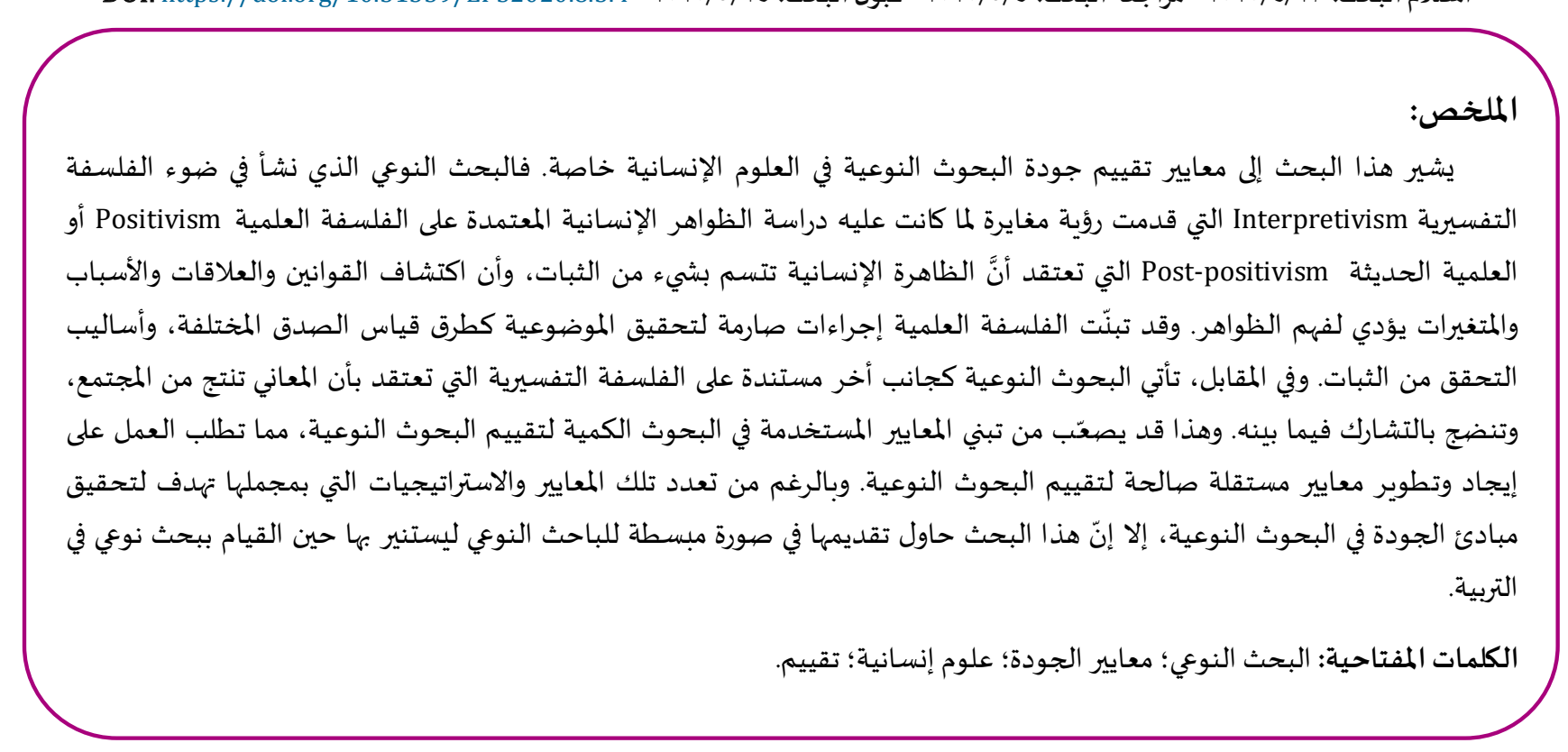

المقدمة:

على الرغم من صعوبة تحديد تعريف عام للبحوث النوعية التي تجمع مجموعة واسعة من المناهج والتصميمات البحثية المختلفة، إلا أنها رغم

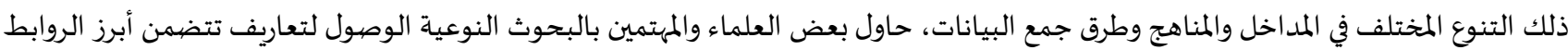

فقد ذكرت مريم (Merriam, 2009,p. 13) بأن البحوث النوعية تهتم بالمعاني التي ينتجها الناس، وكيفية فهمهم لعالمهم، وتجاربهم فيه.

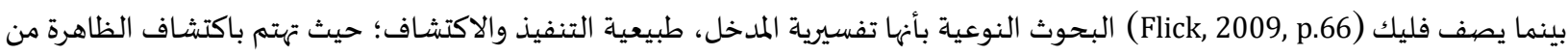
الداخل، متخذة وجهات نظر المشاركين كنقطة لبدايتها.

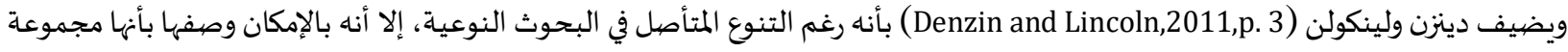

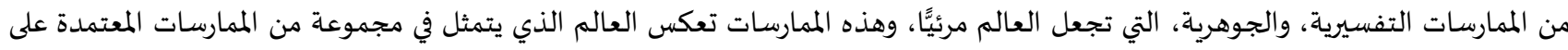

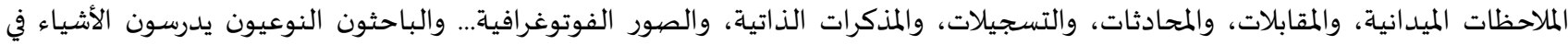

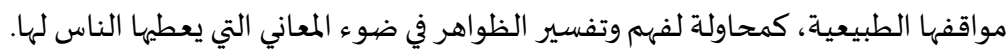
ويعرفها باركنسون ودرسلين (Parkinson \& Drislane, 2011) بالبحث الذي يستخدم طرقًا؛ كالملاحظة، أو دراسات الحالة، التي تقود إلى الى الوصف السردي للممارسات، ويقوم على رفض مبادئ الفلسفة العلمية (الوضعية) Positivism في دراسة الظواهر الاجتماعية، متبنيًا التفسيرية 
et.al., 2007) (Flick, 2018; Strauss \& Corbin, 1998; Willis, وقد حاول بعض العلماء أمثال فيليك، وستراوس وكوربن، وييلس ورفاقه تعريف البحوث النوعياة على نقيض أهداف ومناهج البحوث الكمياة، بينما يعارضهم البعض؛ أمثال سيلفرمان (Silverman,2013) في بناء تعريفات

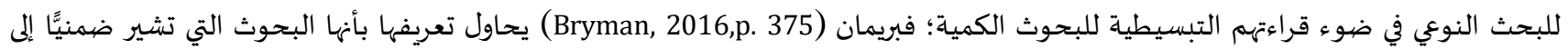

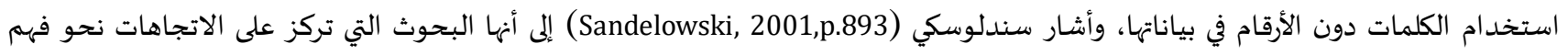
(Hammersley, 2013, p. الظواهر، والخبرات، والتفسيرات الإنسانية للعالم الاجتمائ، وتحقيقها من خلال المشاركين ذواتهم. ولكن يرى هامرسلي

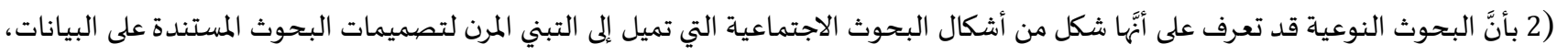

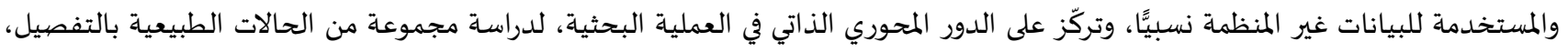

معتمدة على الألفاظ، دون الخواص الإحصائية والحسابية.

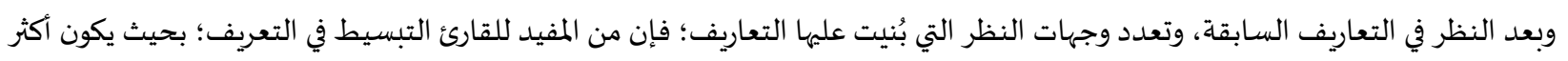

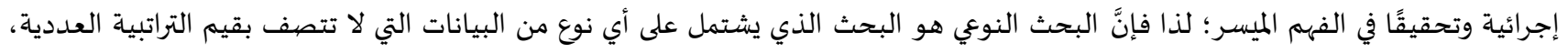

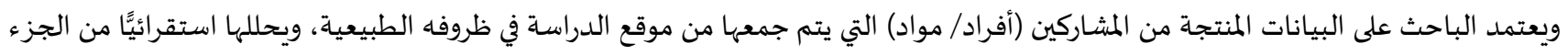

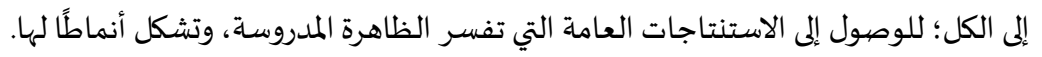

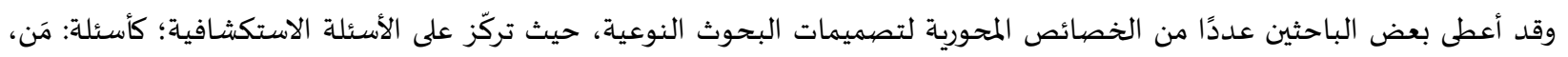

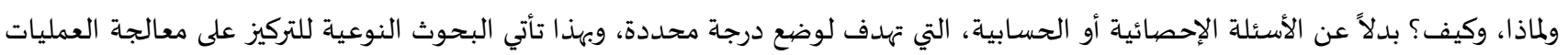

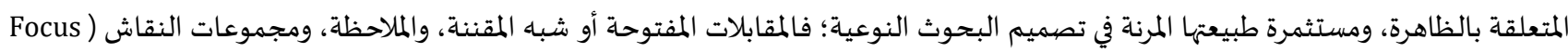

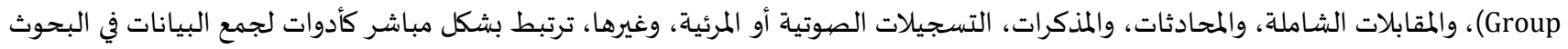
النوعياة.

وتتسم البحوث النوعية بعدة خصائص؛ من أبرزها: اشتراك الأهداف والغايات في تحديد الفهم، والتفسير العميق للعالم الاجتماعي، بواسطة

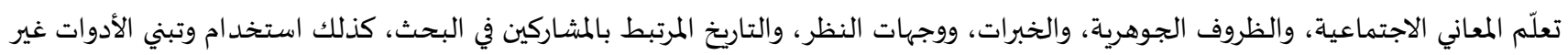

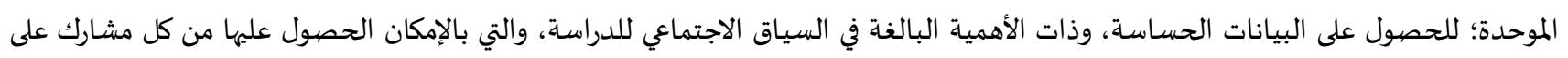

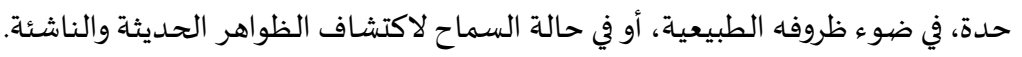

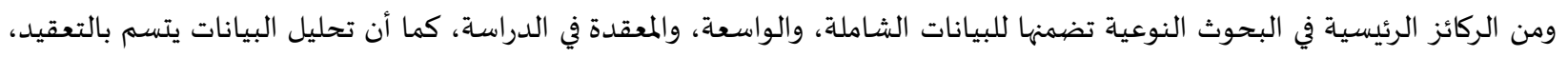
والفوارق، وتقدير الاختلاف بين كل مشارك وآخر، أو تكرار البيانات الواردة من المشاركين، وتصنيفهانيا في محاور رئيسيسية.

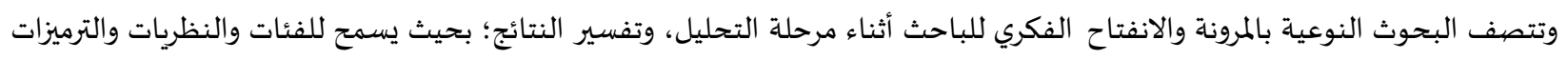

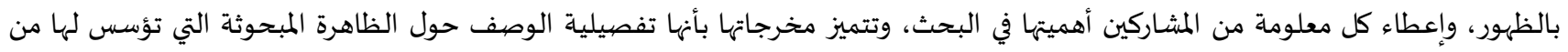
منظور المشاركين واعتباراتهم. إضافة إلى ذلك؛ فإن البحوث النوعية تأملية؛ حيث يقوم الباحث بمراجعة أدواره التي قام بها في البحث، والتي قد تؤثر في النتائج، وكتابة تقرير

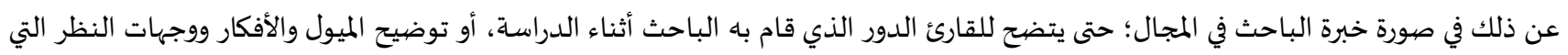
يحملها، مما يعطي مؤشرًا للنزاهة في البحث النوعي (Ritchie, et,al., 2014). ويزيد على هذه الخصائص ماكي وجاس (Mackey \& Gass, 2016) بأنَّ البحوث النوعية تتسم بقلة العينة المشاركة في جمع البيانات مقارنة

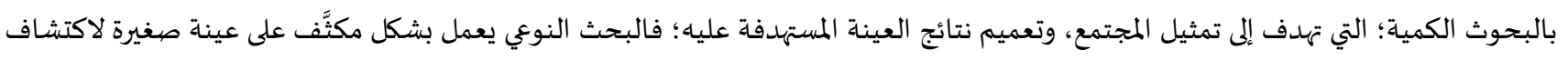

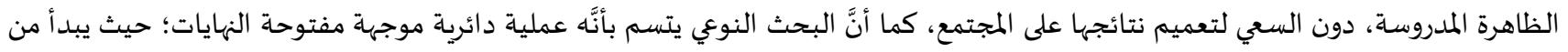

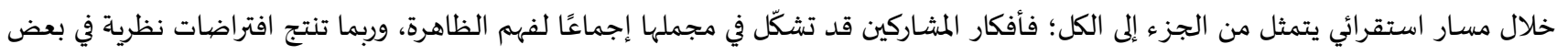
مناهج البحث النوعي. ويعتقد براون (Brown ,2003, 1792) أنَّ إحدى جوانب القوة في البحث النوعي هي تشكيل افتراضات جديدة حول الظاهرة المدروسة حيث الافتراضات تتشكل بالترابط بين ما ينتجه المشاركون من معرفة متواترة ومكررة حول الظاهرة.

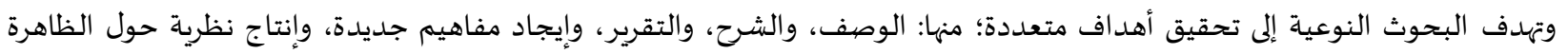

المستكشفة(Cohen, Manion, \& Morrison, 2018) ويتضح من التعاريف السابقة والخصائص العامة للبحوث النوعية في العلوم الاجتماعياة، بأنَّها تتمحور وظائفها في التفسير والشرح للأسباب والروابط التي تتعلق بما هو موجود، أو التقييم الذي يسهم في تقدير وتخمين فعالية ما هو موجود، أو الإنتاج التوليدي الذي يطّور النظريات والإستراتيجيات والأفعال، أو السياقية التي تصف شوجل أونس أو طبيعة ما هو موجود من خلال البحث الوصفي (Ritchie, et.al.,2014). 
ويقدم الجدول (1): مقارنة توضيحية بين وظائف البحوث النوعية والكمية، في ضوء المظاهر الأربعة المقترحة من رتشي ورفاقه (ع ا ـا)، وكيفية تناولها لدراسـة الظاهرة المقترحة من عدة سبل وفقاً لمنطلقاتها الفلسفية المختلفة، ومن خلاله تتضح صورة التكامل فيما بينها.

\begin{tabular}{|c|c|c|}
\hline البحوث الكمية & البحوث النوعية & وظائف البحث \\
\hline 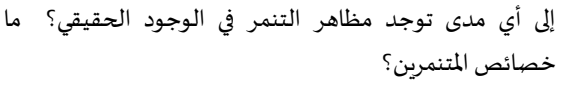 & يعني التنمر؟ طراسيعة الأشكال المختلفة من التنمر المني، والخبرات؛ كماذا & Contextual السياقية \\
\hline معرفة العوامل الإحصائية التي ترتبط بالتنمر، أو الخصائص & 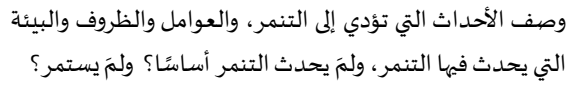 & الوصف والشرح Explanatory \\
\hline 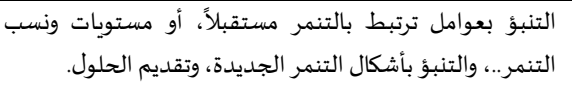 & 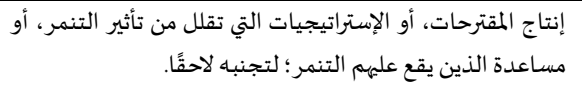 & التوليد/الإنتاج Generative \\
\hline
\end{tabular}

وقد استخلص كل من لينكولن وجوبا، وبولكينهورن أنَّ البحث النوعي يشترك Lincoln \& Guba (1985,p. 39-43; Polkinghorne (2007)

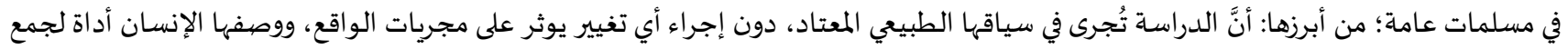

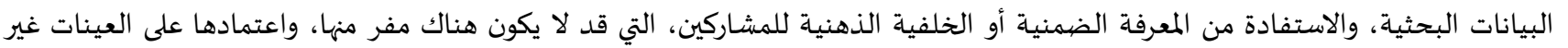
الاحتمالية؛ كالقصدية التي تحقق أهداف الدراسة، وتضيف لها المعرفة، واستخدام المدخل الاستقرائي (Deductive approach) في تحليل البيانات

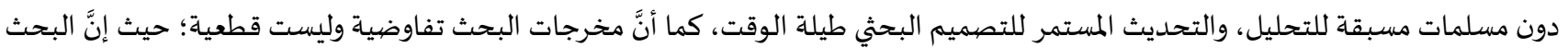
النوعي يرى بأن العالم الاجتماعي غير مستقر؛ فالمعرفة من وجهة نظر النوعيين تتشكل اجتماعيًّا، وهي غير مطلقة أو مجردة، وإنَّما متغيرة ومتعددة

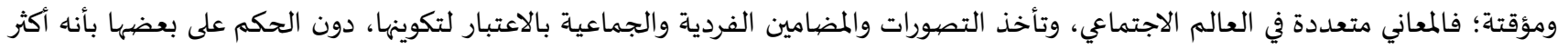

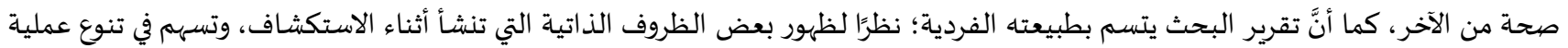

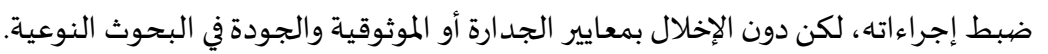

\section{المنطلقات الفلسفية للبحوث النوعية}

تعد العلوم الإنسانية محط أنظار العديد من الفلسفات والنظريات التي تتناول الظاهرة الإنسانية من جوانب مختلفة؛ بوصفها الحقل الخصب

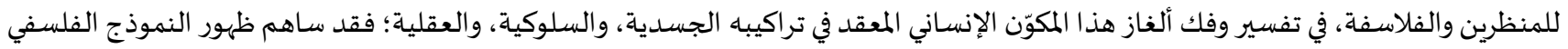

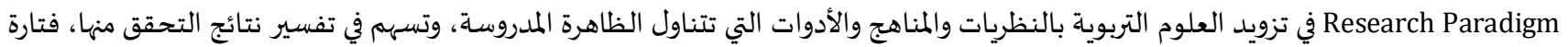

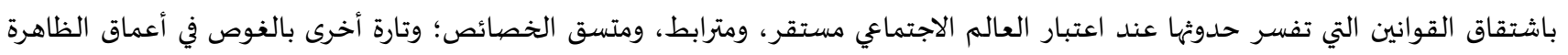

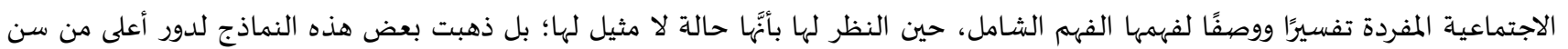

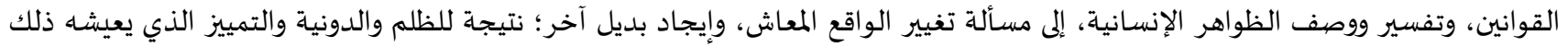

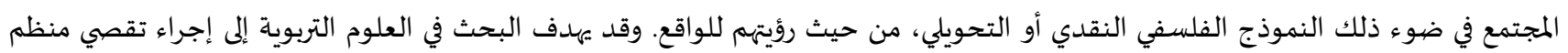

لاكتشاف الظواهر بعمق، وتفسيرها من خلال تفسيرات وتصورات مختلفة؛ تشمل: المواقف، والنماذج الفلسفية المختلفة (Bryman, 2016).

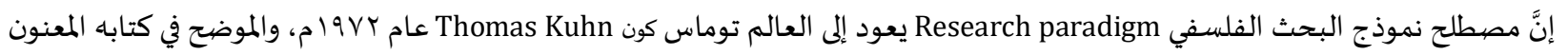
بـ "The Structure of Scientific Revolutions"، والذي يعرفه بأنَّه منظور نظري، يشير إلى كيفية تعامل الباحث مع إجراءات البحث، وكيف صيُمهم

منهج البحث، وكيف قام الباحث بجمع البيانات، وتحليلها، وتفسيرها، ومناقشتها، (Creswell, 2014).

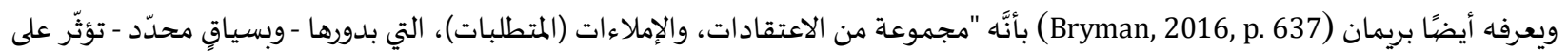

العلماء من حيث ما يجب دراستاه، وكيفية إجراء البحث، وطريقة تفسير النتائج، وهكذا".

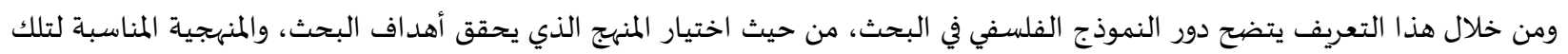
المشكلة، ودور الباحث تجاه التعامل معها، والأدوات المناسبة للإجابة عن أسئلة البحث؛ بل يتعدى دور النموذج الفلسفي إلى تفسير النتائج، ومدى تعميمها من عدماه في العلوم الإنسـانياة. كما أنَّ هناك عدة عوامل تؤثر في اختيار النموذج الفلسفي؛ منها: الافتراضات نحو الحقيقة، وطبيعة المعرفة في البحث، والإطار النظري، والأدبيات البحثية السابقة للظاهرة محل الدراسة، ومنظومة القيم، والمفاهيم الأخلاقية التي تبنّها عملية البحث ( Wagner, Kawulich, 
وتتفق الأدبيات البحثية السابقة في وجود أبرز خمسة نماذج بحثية فلسفية قد يستخدمها الباحث في العلوم الإنسانية، والتربوية خاصيةً؛ ليجيب

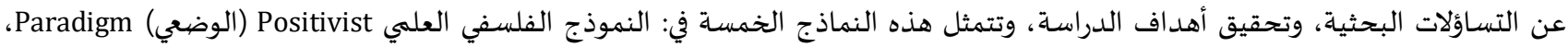

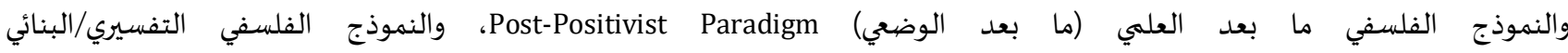
Interpretivist/Constructivist Paradigm والنموذج الفلسفي التحويليTransformative Paradigm أو النموذج النقدي Critical Theory،

والنموذج الفلسفي البراغماتي/النفعي Crotty,2015;Creswell\&Clark,2011;Pring,2015; Wagner, et., al.2012)Pragmatism Paradigm).

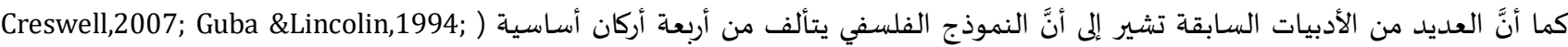

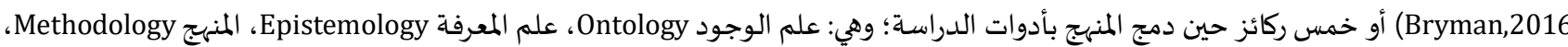

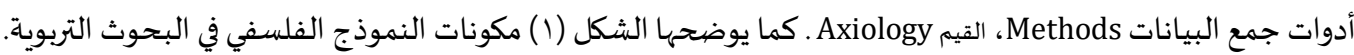

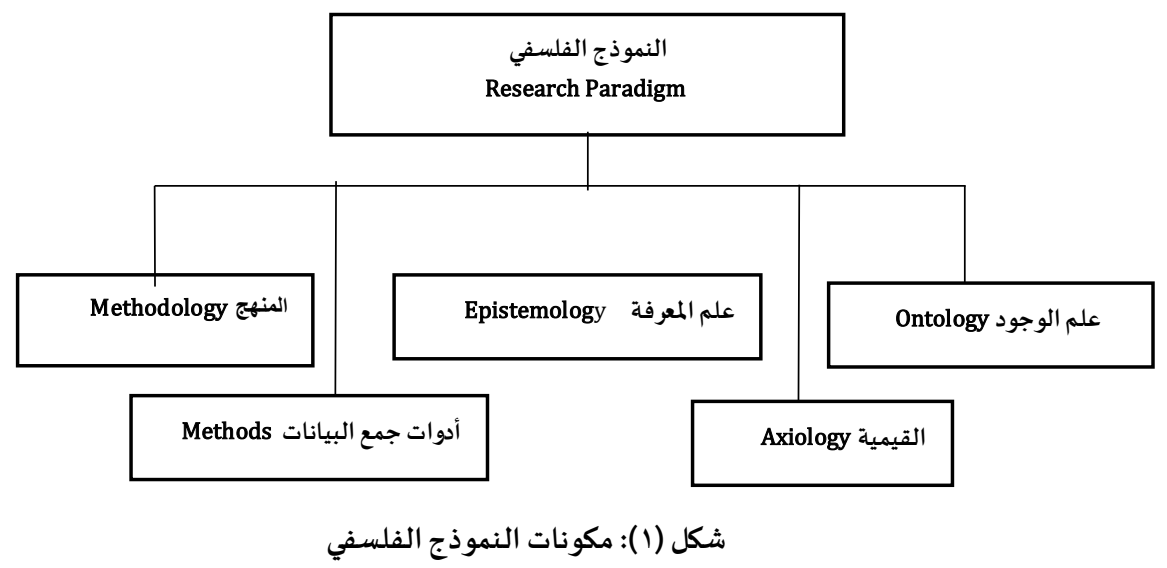

ومن المفيد هنا الإشارة بشيء من التفصيل إلى العناصر المكونة للنموذج الفلسفي، دون التوسع في استدعاء التاريخ الجدلي الواسع والمتناقض أحيانًا بين العلماء فيها؛ فالهدف الإشـارة إلى المصطلحات بشيء من التمهيد؛ حتى يتسنى للقارئ فهم تلك المكونات عند تناولها في كل نموذج فلسفي.

فيُعرَّف الوجود Ontology بدراسة الواقع، وطبيعة الحقيقة، المتمركزة حول السؤال "ما طبيعة الوجود؟" (Crotty, 2015). ويضيف جوبا Guba (1990) بأنَّ السؤال الوجودي يسأل عن طبيعة الواقع. ويعتمد البحث النوعي على مبادئ النموذج الفلسفي التفسيري (البنائي )، الذي يفترض بأنَّ الوجودود أو الواقع متعددد؛ حيث يسعى الباحث

لاكتشافه من خلال المعاني، والمفاهيم الإنسانية المشتركة (Henn, Weinstein, \& Foard, 2005). كما أن الواقع أو الحقيقة جزء مما يتصوره العقل الإنساني، الذي بإدراكه لها تتكون المعاني والتفسيرات للحقيقة والواقع، وبناء على الفهم، التهاء

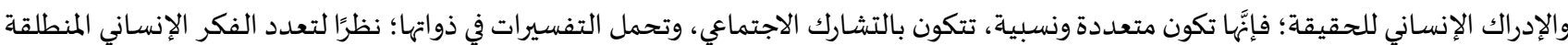
منه، والمنبثقة مما يدركه حول الظاهرة، كما أنَّا نسبية غير مطلقة (Newman \& Benz, 1998).

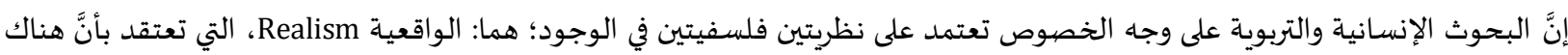
واقعًا موجودًا، وعالماً مستقلًّا عن الباحث، وما عليه إلا اكتشاف القانون المسير لذلك الواقع وإدراكه (Pring,2015)، والنظرية النسبية Relativism) التي تتناسب مع البحث النوعي، والمرتكزة على أنَّ الحقيقة غير مطلقة، وإنَّما نسبية ذاتية إلتية تتكون من خلال العقل الجمعي للمشاركين، وتفسيراتهم للظاهرة المدروسـة.

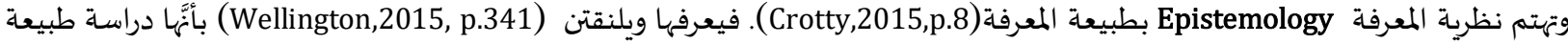
وصحة المعرفة الإنسانية. وتحدد نظرية المعرفة العلاقة بين الباحث، والواقع المراد معرفته، مقسمة ذلك إلى قسمين، اعتمدت عليهما المداخل الكمية والنوعية؛ فالمنظور

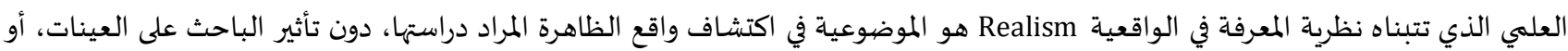
البيانات، فالحقيقة تقع خارج تصوره الذهني، بحيث تكون قيم الباحث، ومبادئه، وتأثيره معزول عما سيدرساء؛ فيتقصى الظاهرة بشكل موضوعي

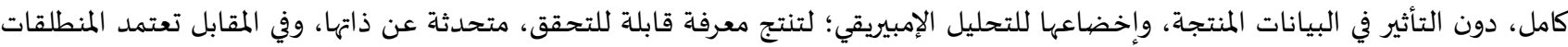

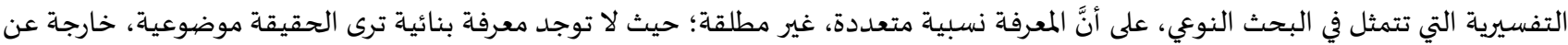
التصور الإنساني، وتنتظره لاكتشافها؛ فالمعاني تدرك بتشاركها، وبنائها اجتماعيًًا (Crotty,2015).

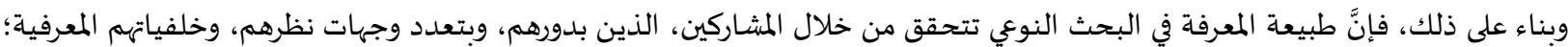
يكونون المعرفة حول الظاهرة المراد دراستها. 
والمنهج Methodology هو خطة، أو إستراتيجية؛ لتبرير استخدام أو اختيار طرق جمع بيانات محددة دون غيرها (Crotty, 2015). بينما يرى مارجيك، ديمتيو، و فيستنجر (Marczyk, DeMatteo, \& Festinger, 2005) بأنَّا "المبادئ والإجراءات التي تضبط البحث، مئه وتوجهات

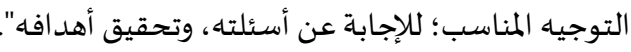
ويعرفها ويلنقتن (2015) على أنَّها نشاط وتجة أو مهمة اختئيار الأساليب، وتقييم ذلك الاختيار، والتبرير لاستخدام أدوات جمع بيانات Methods دون

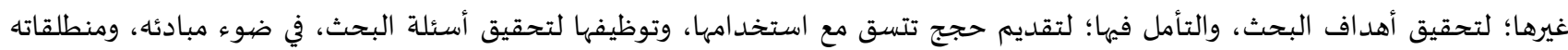
الفلسفية (Wellington, 2015, p.33). فالبحوث النوعياة تعتمد على المدخل الاستقرائي Inductive Approach، الذي يبدأ من الجزء إلى الكل Bottom-up، وتتعدد مناهج البحث

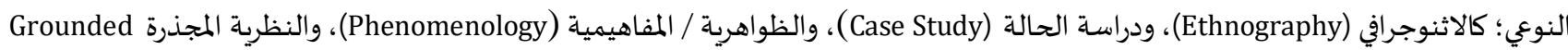
(Theory)، والتأويلية (Hermeneutics). والقيمية Axiology علم يهتم بدراسة القيم والأخلاقيات. (Kneller, 1971).

\section{متى تستخدم البحوث النوعية}

تستخدم البحوث النوعية للإجابة عن الأسئلة المتعلقة بالتجارب الشخصية، والمعاني، والتصورات، والمنظور الجمعي لوجهات نظر المشاركين في

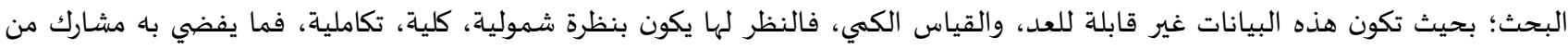

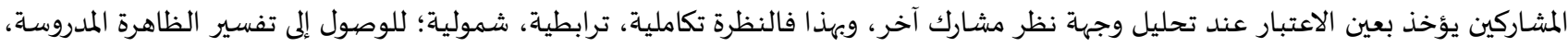

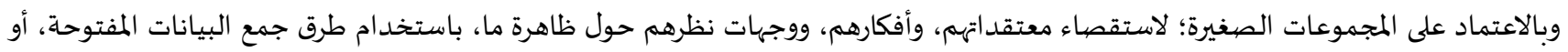

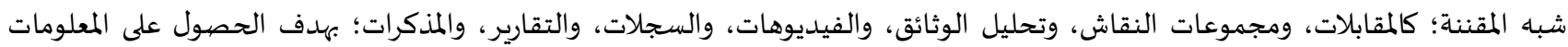
الرئيسية التي تسهم في فهم الظاهرة فهمًا واسعًا. وتتعدد المبررات لاستخدام البحث النوعي؛ فمنها: الحاجة لإنتاج نظرية تفسر الظاهرة الإنسانياة، دون استعارة النظريات العلمية من مجالات العلوم المختلفة عن السياق التربوي؛ فمجال العلوم الإنسانية أصبح لدياء القدرة على إنتاج نظريات تفسر الظواهر والقضايا الإنسانية، في ضوء

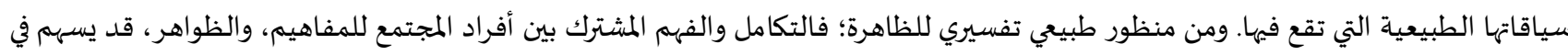
معالجة الكثير من التساؤلات والمشكلات الاجتماعية، وإنتاج المعارف المثمرة حولها، بعيدًا عن إسقاط القياسات، والاختبارات الموضيوعية على المجتمع ،

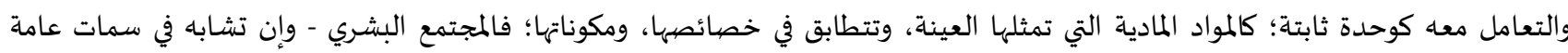
وخصائص مشتركة - إلا أنَّ هناك العديد من العوامل الظاهرة والخفية التي تؤثر فيه، وتسهم في تطوره؛ فالإنسان نمائي بطبيعته الخلقياة، وتطوري

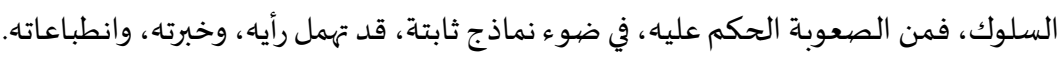

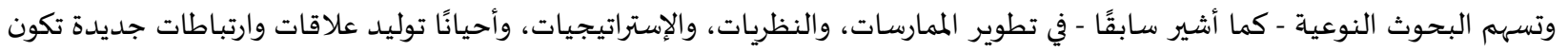

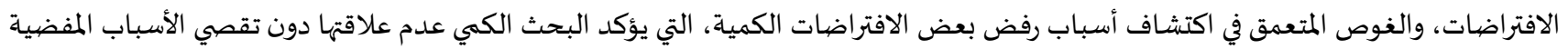
لذلك الرفض من وجهة نظر فلسفية مختلفة. فيأتي البحث النوعي ليكتشف الأسباب الكامنة، التي كانت وراء عدم ارتباط المتنيرات، وإبراز الأنماط المتعلقة بتلك النظريات، وسياقاتها، بطريقة منظمة، وواضحة، تكشف تلك الأدلة التي أدت لرفض الفروض (Patton,1990). وفي المقابل، وبالرغم من الدور الذي تسهم فياء البحوث النوعية في تطوير وتحسين النظريات، إلا أنَّ البعض يعتقد بأنَّ البحوث النوعية قد ادلد

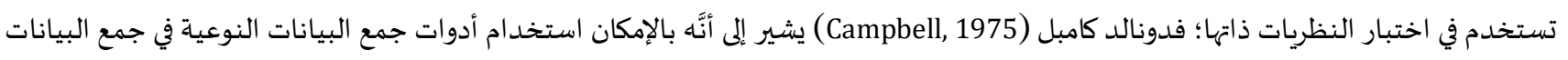

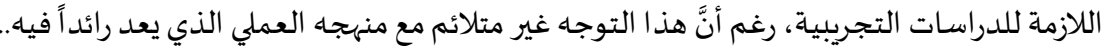

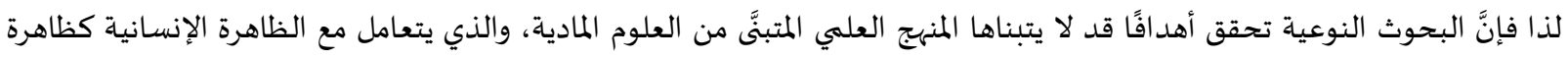
كونية مادية ثابتة، حين اكتشاف قانونها يسهل التعامل معها والتحكم فيها. وقد أورد نيومان وبنز (Newman \&Benz, 1998) بأنَّهَ وإن بدا في الظاهر التناقض بين المداخل البحثية الكمية والنوعية، إلا أنَّا في الواقع نهايتين مختلفتين، على خط متصل واحد، تتوسطها البحوث المختلطة.

$$
\text { الجودة في البحوث النوعية }
$$

تعد الجودة الركيزة الرئيسية في أيّ عمل بشكل عام، فكيف بها في البحث العلمي الذي يعرف على أنَّه عمل منظم في جميع خطواته؛ من مراحله الأولى، وصولاً لجمع البيانات، وتحليلها، وتفسيرها، وكتابة التقرير النهائي الذي يتضمنها كمنتج نهائي لهذه العملية البحثية. فمن المعتاد عند تناول

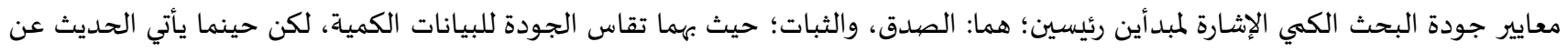


البحوث النوعية فإنَّ الأمر يزداد تعقيدًا نوعًا ما؛ حيث إنَّ الحكم على البحوث النوعية قد لا يتبع الإجراءات التسلسلية والثابتة، المعمول بها في

البحوث الكمية؛؛ وذلك لتعدد المناهج التي تقع تحت مظلة البحث النوعي، وتنوع طرق جمع البيانات النوعياة، وأساليب تحليلها، وتفسيرها.

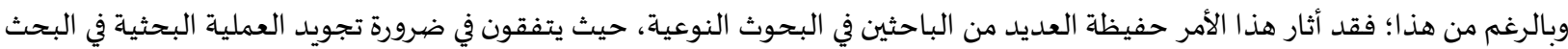
(Altheide \& Johnson,1994; Hammersley,2005; النوعي، باستخدام أدوات لقياس الجودة في البحوث النوعية غير المعمول بها في البحوث الكمية Lincoln \& Guba, 1985).

ولهذا الرأي ما يبرره من حيث اختلاف المنطلقات الفلسفية لكلا المدخلين، كما جاء سابقًا عند تناول الفلسفة الواقعية والفلسفة النسبية، المختلفتين في رؤيتهما للوجود، والمعرفة.

وقد ساهم غياب المعايير الخاصة بجودة البحوث النوعية في محاكمتها وفقًا لمعايير البحوث الكمية؛؛ حيث أدى ذلك للحكم على ضعفها، وتدني

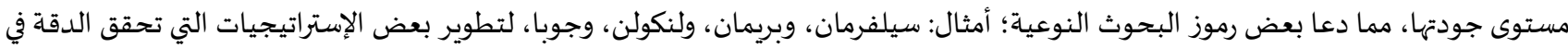
المنهج النوعي، وفي جمع البيانات التي تعد إرشادات عامة وتوجيهية للباحثين، والمبتدئين في البحوث النوعية، فتنير لهم ما يأخذونها في الاعتبار عند

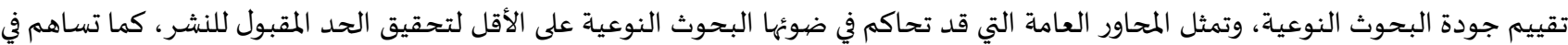
خدمة المؤسسات والجهات الممولة والراعية للبحوث النوعية، حين ترغب معرفة مدى جودة البحث الممول من قبلها، ومدى إتقانه ; Guba and Lincoln,1994; Silverman, 2013) وقد تباينت آراء العلماء حول نوعية المعايير التي تُتبنَّ للحكم على جودة البحوث النوعية؛ فقد صنف علي ويوسف (Ali \& Yusof, 2011) هذا التباين إلى التصنيفات التالية:

توحيد معايير الحكم على جودة البحث العلمي، دون النظر فيما يتبناه من مداخل، أو منطلقات فلسفية؛ حيث يرى هذا الفريق ضرورة الطريقة الواحدة للحكم على الدراسـات النوعية، ولكنه اقترح معايير الحكم على البحث الكمي؛ المتمثلة في: الثبات، والصدق الداخلي، والصديدق الخارجي، والموضوعية، وهذه المعايير في ذاتها قد لا تتناسب مع البحث النوعي، وطبيعة الحكم عليه في ضوهئها يضعفه - كما ورد أعلاه -. عدم تبني طرق ووسائل للحكم على الدراسات النوعية؛؛ لتنوعها، واختلاف مناهجها، وأدوات جمع بياناتها، والظروف التي ينتج فيها البحث النوعي؛

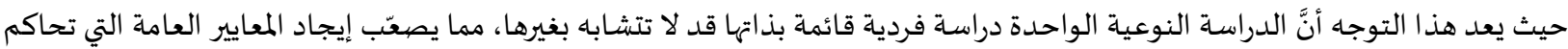

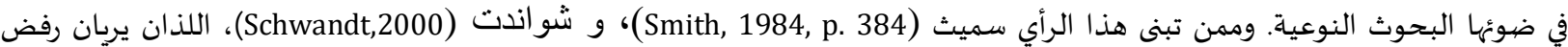

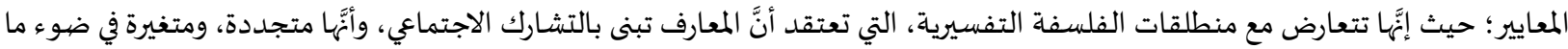

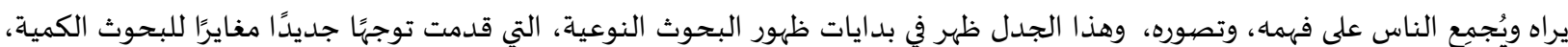

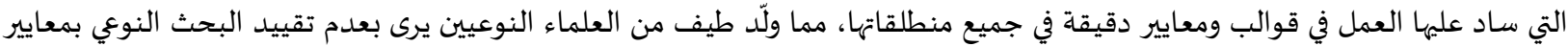

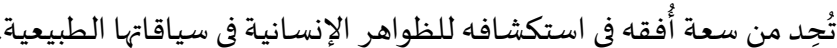
بينما يدعو فريق ثالث من العلماء إلى الاستفادة من المعايير المستخدمة في الدراسات الكمية، وتعديلها بما يتوافق مع السياق المناسب للدراسات النوعية.

ويرى أخر تطوير معايير خاصية بالبحث النوعي. فبما أنَّه مخرج للفلسفة التفسيرية، التي تتعارض منطلقاتها مع الفلسفة العلمية (الوضعية)، بحيث تكون هذه المعايير قادرة على الحكم على جودة هذا البحث دون غيره؛ فالفلسفة بطبيعتها العامة قادرة على تقديم تصور عام لما هو أعلى

من المعايير، والمؤشرات؛ كتقديم تصور عام للكون، والحياة، والإنسان. ويتضح من تلك التصنيفات اتفاق الكثير من الآراء على ضيرورة إيجاد المعايير والطرق والوسائل والمؤشرات التي تضبط ونيط جودة البحث النوعي،

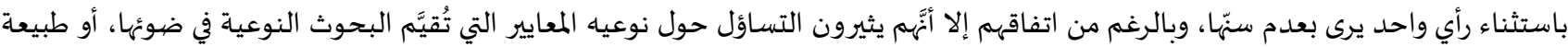

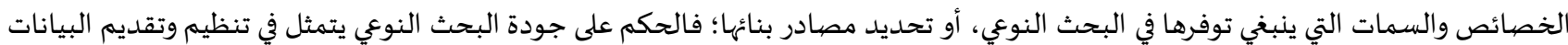
النوعية، وإخراجها في محتوى مفهوم ومترابط ومنطقي للقارئ؛ فالكفاية في جمع البيانات، وتحليلها، والاستفادة منها، وتنظيمها، وتفسيرها تفسيرًا

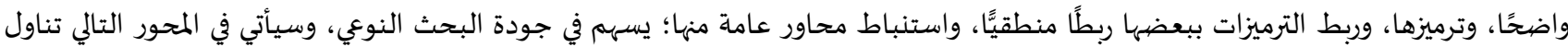

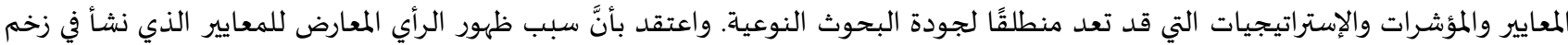

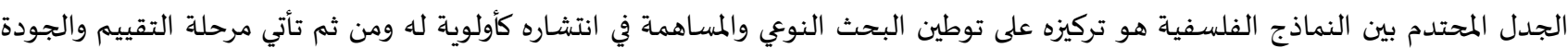
والتأمل في الإجراءات. 
معايير جودة البحوث النوعية

بعد استعراض الحاجة إلى معايير الجودة في الدراسات النوعية، وتباين الآراء حولها في القسم السابق، يأتي النقاش في هذا القسهم حول مجموعة من المقترحات لإستراتيجيات وطرق تحقيق الجودة في البحوث النوعية، وعلى الرغم من صعوبة إيجاد معايير ثابتة تتلاءم مع تصميمات البحات البحوث النوعية المختلفة، إلا أنَّ هناك بعض التشياس وطرف التشابه في معايير التقييم كما سيأتي لاحقًا. فيقترح ريد وكاف (2000) Reid and Cough بأنَّ معايير جودة البحوث النوعية تتمثل في مقترحات لقائمة من الأسئلة، التي بمجملها قد تُؤدي إلى إلى

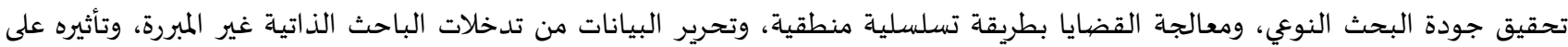
مخرجات البحث، وتحديد الدور الذي يقوم باه في مجريات البحث النوعي.

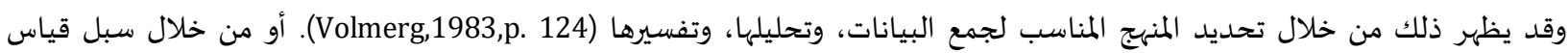

الموثوقية المختلفة؛ كالصدق التراكمي، أو الصدق التواصلي، أو السياقات البيئية (Köckeis-Stangl, 1980). فتحقيق الصيدق والثبات ليس حصبرًا على البحوث الكمية فحسب؛ فالبحوث النوعية تهتم بتحقيق الموثوقية والمصيداقية بطرق متعددة، وتحت مسميات مختلفة، ههدف في مجملها إلى تحقيق جوانب القوة في البحث؛ كمسمى المصداقية، وقابلية النقل، والاعتمادية، والتأكيدية، والتي سيشار إلهيها

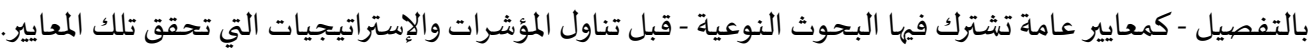
إنَّ البحوث النوعية تتبنى مجموعة من الطرق المختلفة؛ للتأكد من الصيدق والثبات الذي يعبَّر عناه بمصطلح الموثوقية Trustworthiness، فيورد سـارانتيكوس (Sarantakos, 2012) بأنَّ الصدق التراكمي Cumulative validity هو الذي تقارن فياه نتائج الدراسة الحالة بنتائج الدراسات

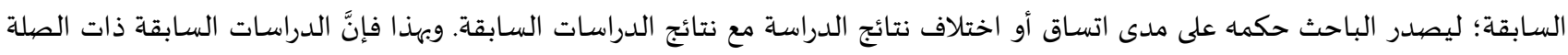

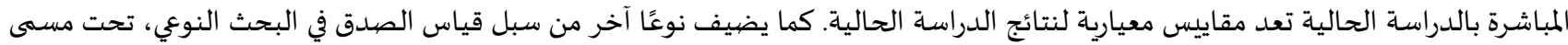

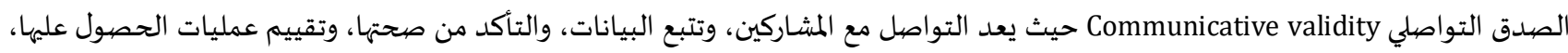

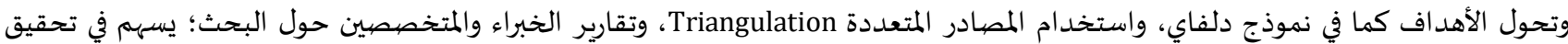

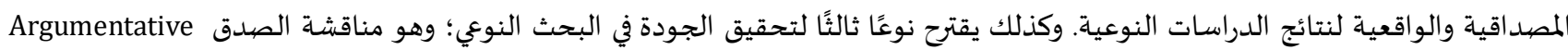
validity؛ حيث يعد شكلاً من أشكال تحقيق الصداق، يتمثل في تقديم نتائج الدراسة بطريقة ههائية قابلة للاختبار، والتتبع، ويختم بالشكل الرابع من

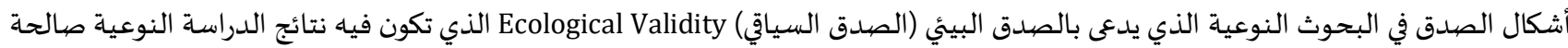

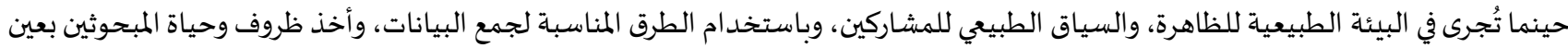

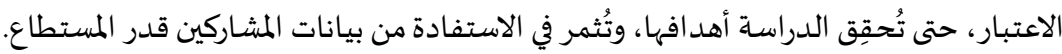

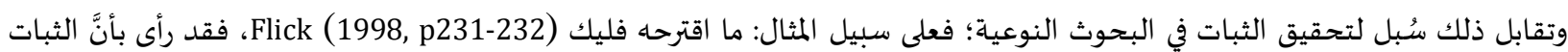
النوعي يتحقق من خلال تحقيق الإجراءات التالية:

Peer Review or deliberating مراجعة الرفاق ومناقشتهم:

تحليل الحالات السلبية Analysis of Negative Case

مراجعة المصطلحات المناسبة عند تفسير النتائج والتأكد من دلالاتها. Checking inappropriate terms

تدقيق المشاركين الأصليين في البحث لتحقيق الصدق التواصلي. Member Checks

التدقيق الخارجي External Auditing.

ويضيف درو وهاردمان وهارت (Drew, Hardman, \& Hart, 1996, p. 169) إلى ما اقترحه فليك مجموعة أخرى؛ تتمثل في التالي:

خفض مستوى الوصف الاستدلالي Use low inference descriptor

Multiple researchers as possible تعدد الباحثين قدر المستطاع

إنشاء سجل التدقيق، ليتضمن مثلاً التسجيلات الصوتية؛ للتحقق منها، ومراجعتها أثناء التحليل، والتفسير Create audit trail.

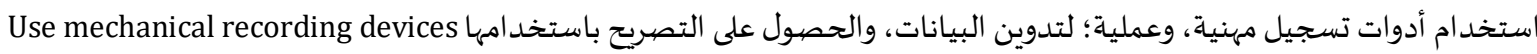
Use participant researchers to check of the accuracy استخدام الباحثين كمشاركين ليتأكدوا بدقة من تصورات ووجهات نظر المشاركين of perceptions إنَّ ما ورد أعلاه من طرق لتحقيق الموثوقية في البحوث النوعية يعد مؤشرات وإستراتيجيات تفصيلية؛ لتحقيق الجودة في الدراسات النوعية؛

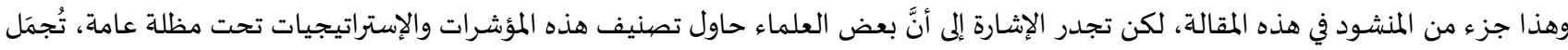
تحتها مجموعة من المعايير، والإستراتيجيات. 
فمنذ التسعينات اهتم لنكولن وجوبا (Lincoln \& Guba, 1985)بمحاولة تحديد وتطوير معايير للبحوث النوعية؛ لترادف وتقابل مظاهر

(Ary, Jacobs, الصدق والثبات في البحوث الكمياة، وقد نجحا وغيرهما من العلماء؛ أمثال: أري، يعقوب، سورينسن، رازافيه، وكرفتنق وشينتون Sorensen, \& Razavieh, 2010; Krefting, 1991; Shenton, 2004)

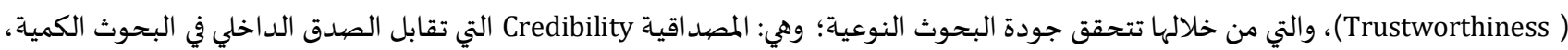
وقابلية النقل/ التعميم Transferability الذي يقابل الصدق الخارجي، أو التعميم، والاعتمادية Dependability التي ترادف مفهوم الثبات، والتأكيدية Confirmability التي تقابل مفهوم الموضوعية الموضحة في الجدول (o) المضيمن بملاحق الدراسة. فيعرف بريمان (Bryman, 2016, p. 697 الموثوقية Trustworthiness بأنَّا مجموعة المعايير التي يدعو إلها الكُتَّاب، والباحثون؛ لتقييم جودة البحوث النوعياة.

جدول (r) ) مقارنة بين معايير الجودة في المدخلين النوعي والكمي

\begin{tabular}{|c|c|c|}
\hline البحوث الكمية (العلمية) & البحوث النوعية (الطبيعية) & 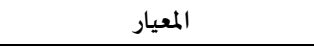 \\
\hline الصداق الداخلي Internal Validity & المصداقية Credibility & صحة القيم Truth Value \\
\hline الصددق الخارجي/التعميم & $\begin{array}{c}\text { قابلية النقل / التعميم } \\
\text { Transferability }\end{array}$ & التطبيق Applicability \\
\hline Reliability الثبات & الاعتمادية Dependability & الثبات Consistency \\
\hline الموضوعيةObjectivity & التأكيدية Confirmability & الحيادية (عدم التحيز) Neutrality \\
\hline
\end{tabular}

Credibility المصيداقية يعرف ليشمان (Lichtman, 2013) مصطلح المصيداقية أو تقدير الحقيقة بأنَّهَ تقييم نتائج الدراسة من خلال وجهات نظر المشاركين، وتعبير

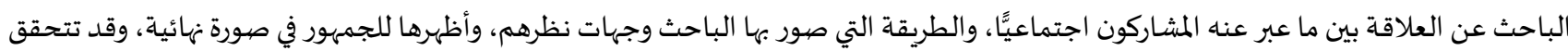

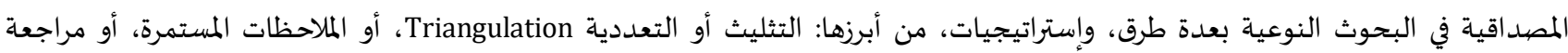

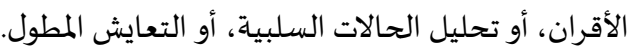

التثليث / التعددية Triangulation التعددية أو التثليث من مظاهر تحقق المصدداقية في البحوث النوعية، والذي يشير إلى تطبيق أكثر من طريقة بحثية لدراسة الظاهرة الواحدة، أو من خلال الجمع بين العديد من الباحثين، واستخدام أكثر من نظرية لتفسر النتائج، وبالتالي هو الجمع بين المصادر المتعددة؛ للتحقق من الفهم الناتج من البيانات بصورة دقيقة. فيعرف دينزن (Denzin,1978) التثليث أو التعددية بأنه مصطلح مستورد من العلوم الملاحية والمسح الجيولوجي للأراضي يشير إلى استخدام مصدرين أو أكثر لتحقيق الصهورة الشاملة من نقطة مرجعية محددة.ويقترح أربعة مظاهر لتحقيق التثليث في البحوث النوعية مجملها موضح في (ب) الشكل (ب)

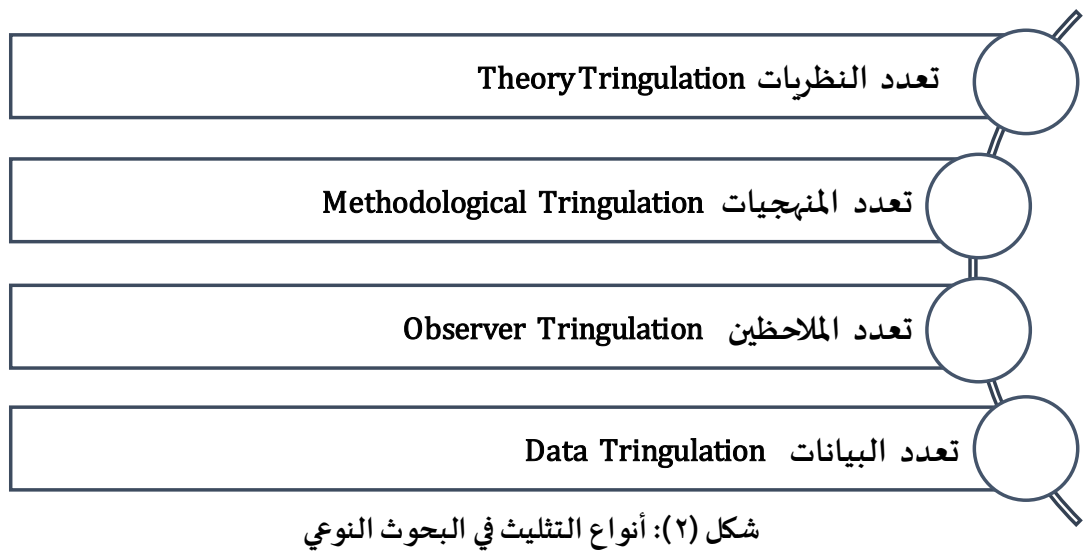

ومن المهم الإشارة إلى أن استخدام هذه الأساليب لتحقيق المصداقية لا يعني بأي حال من الأحوال وجوب تطابق البيانات المنتجة من التنوع،

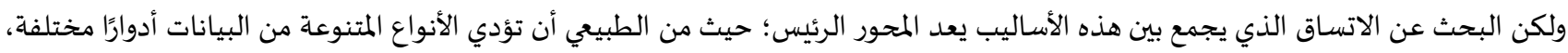

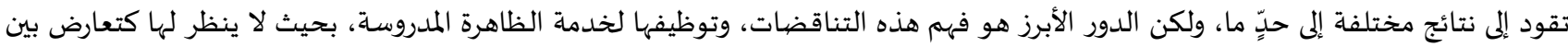
النتائج؛ بل تكامل بينها؛ فالمعاني تعرف أحيانًا بأضبد ادها، مما يمنح الباحث الفرصائ في التأمل والاكتشاف المتعمق للظاهرة المدروساة. 


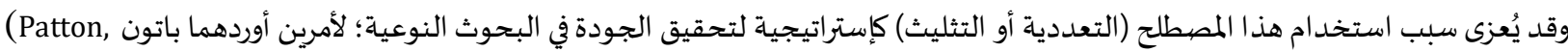

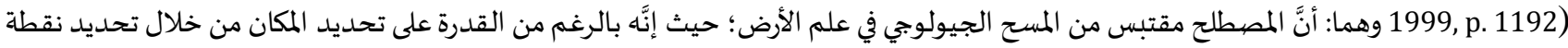

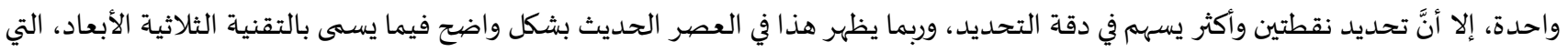
تجعل الأمر أكثر وضوحًا ودقة عند تحديد أكثر من نقطة.

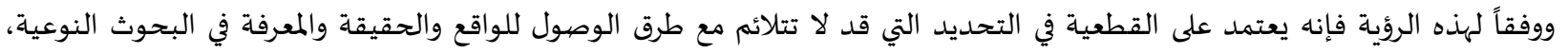

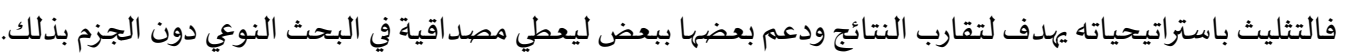

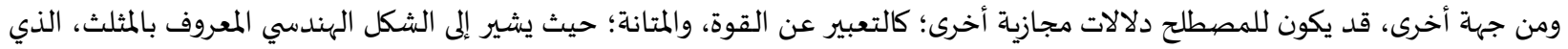

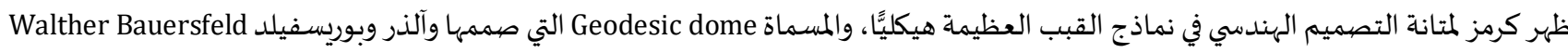

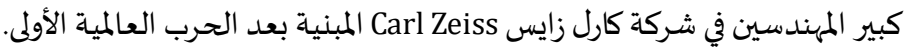

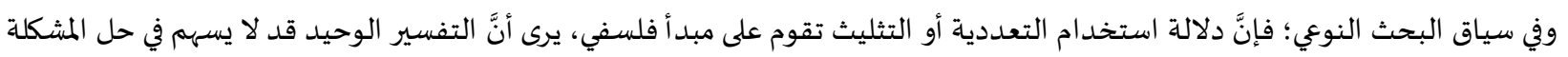

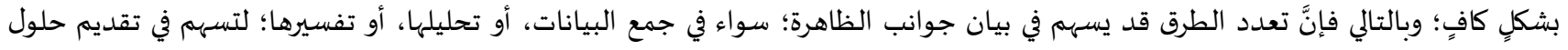

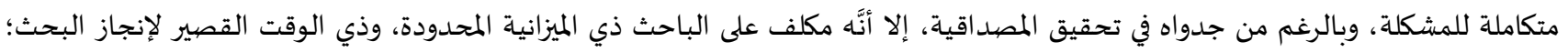

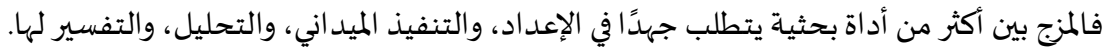

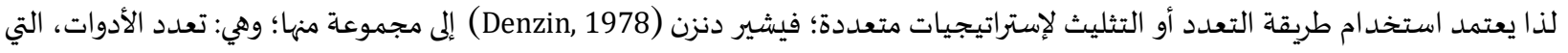

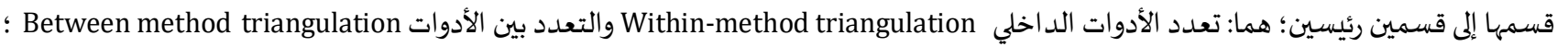

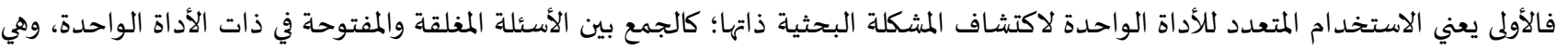

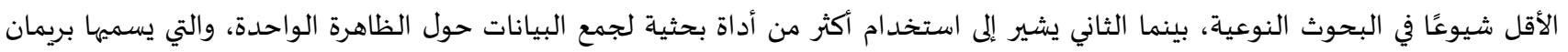

Bryman أدوات البحث المتناقضة "Contrasting research methods".

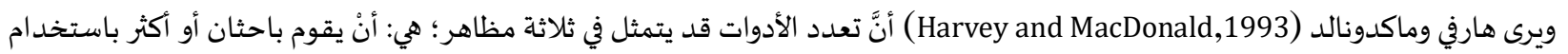

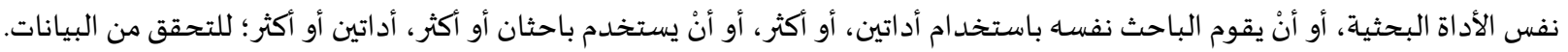

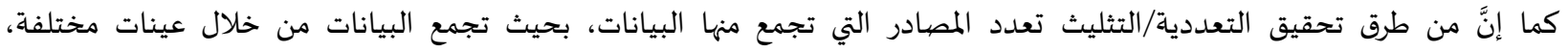

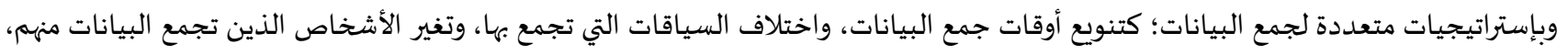

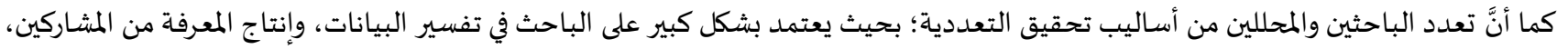

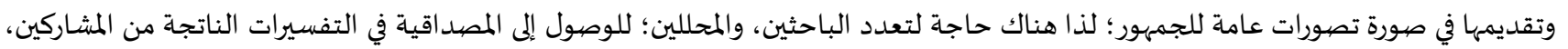

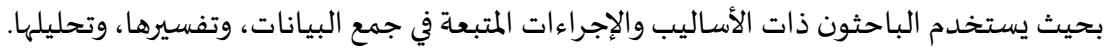

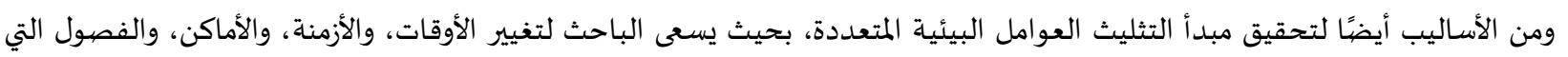
تجمع منها البيانات؛ ليحقق مبدأ المصديداقية.

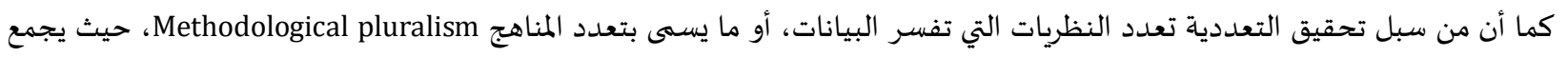
الباحث بين عدة نظريات مختلفة؛ لتفسير الظاهرة المدروسة؛ مثل النظرية المعرفية، أو البنائية الاجتماعية الثقافية؛ لتحقيق مبادئ المصدداقية في البحث النوعي.

قابلية النقل / التعميم Transferability External Validity إنَّ قابلية نقل نتائج الدراسات النوعية مصطعح يقابله تعميم النتائج في البحوث الكمية، أو ما يسهى بالصداق الخارية

.(Seale, 1999)

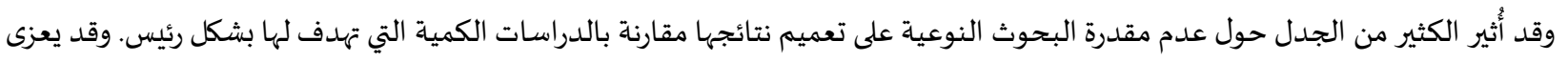

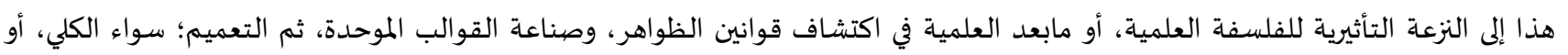

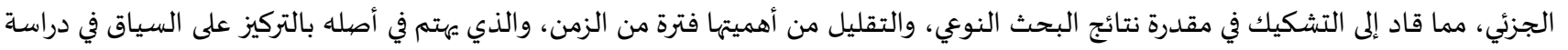

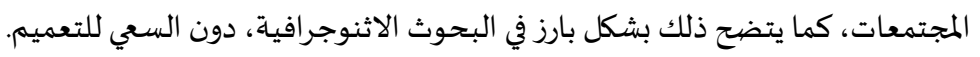

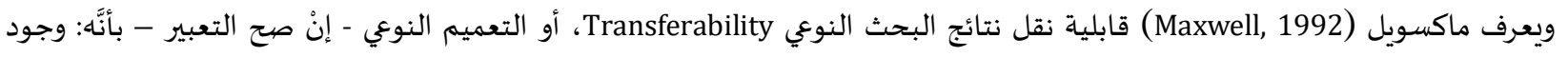

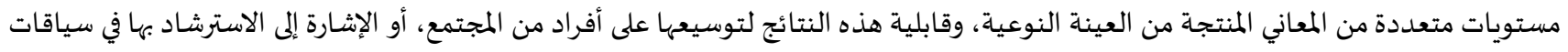

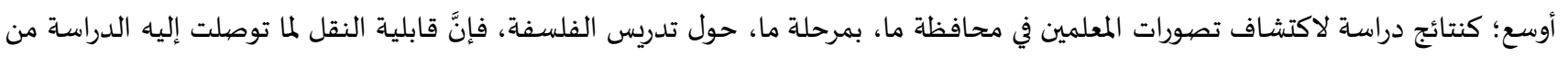
نتائج، قد يسترشد به دون قطع حين تطبيق ذلك على عينة مختلفة، في سياق آخراف ، بمرحلة مختلفة، وبمحافظة أخرل أخرى. 
ويقدم لينكولن وجوبا (Lincoln \& Guba, 1985, p. 8) وصفًا لقابلية النقل بأنَّا "درجة التشابه بين الموقف الأصلي، والموقف المنقول إليه".

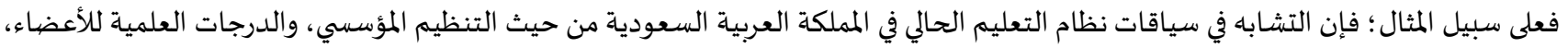

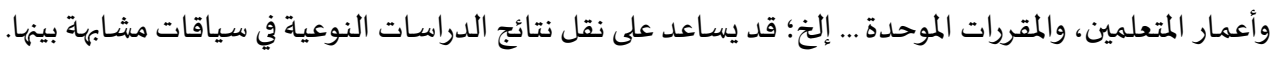

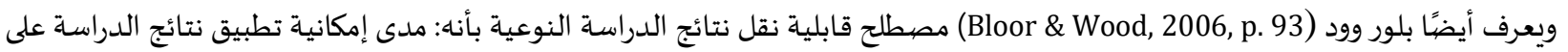

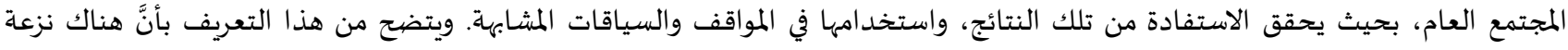

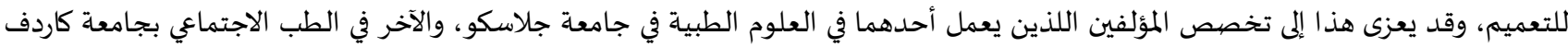
البريطانية، والذي قد تغلب عليه الفلسفة العلمية في دراسة الظواهر.

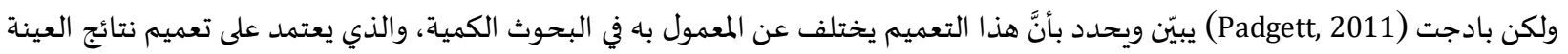

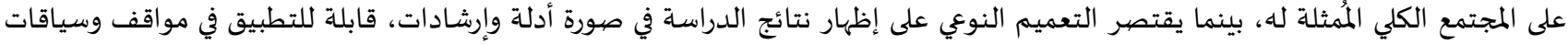
مشابهة في المجتمع.

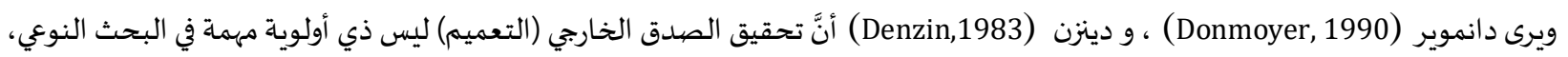

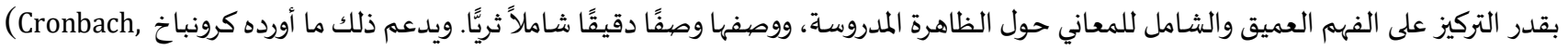
(1975, p. 124) حينما ذكر بأنَّ الظواهر الاجتماعية ذات سياقات محددة، يصعب تعميم نتائجها.

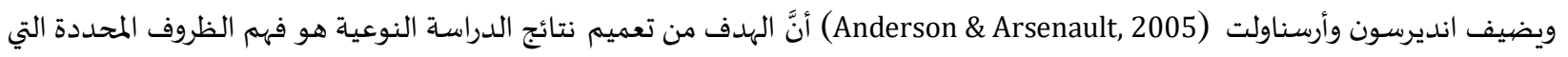

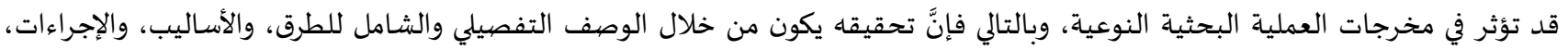

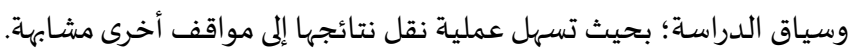
ويصف هامبرييرج، كيركمان، دي ليسي (Hammarberg, Kirkman, \& de Lacey, 2016) الدراسة النوعية بأنَّا تستوفي شرط القابلية للنقل

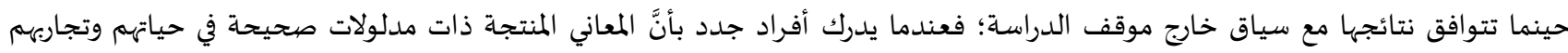

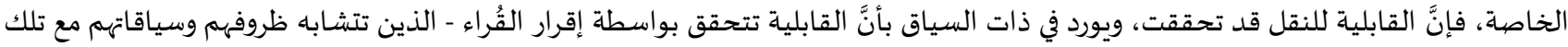
المخرجات - للنتائج.

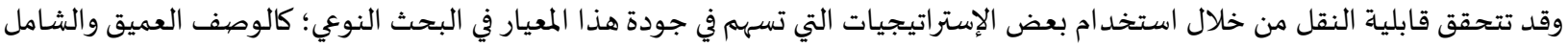

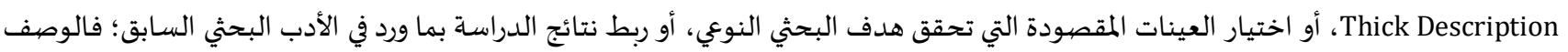

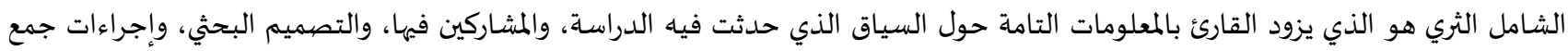
البيانات؛ بحيث يتيح للقارئ الحكم على مدى قابلية النقل من عدمها للفئ للنتائج.

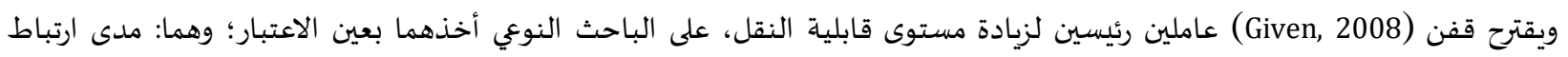

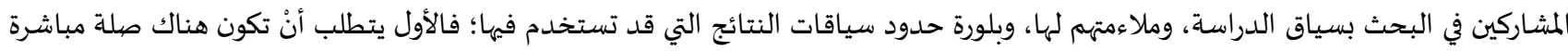

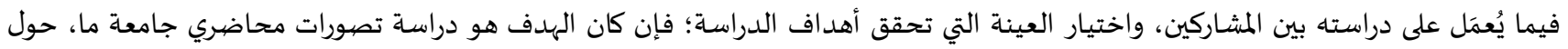

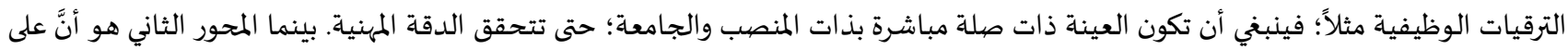

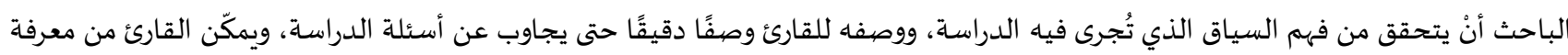

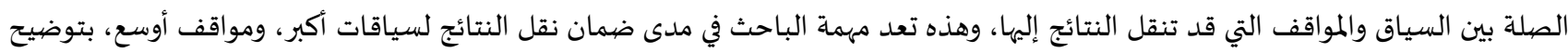
تفاصيل السياق الذي أجرى فياء الدراسة.

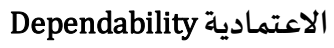

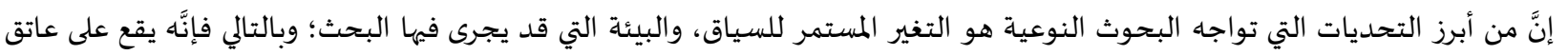

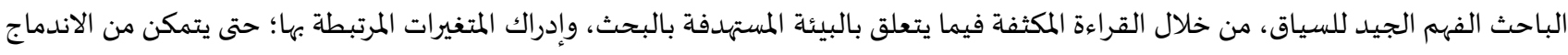

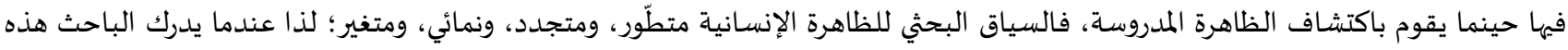

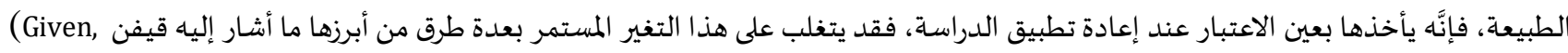

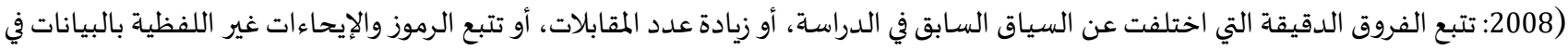

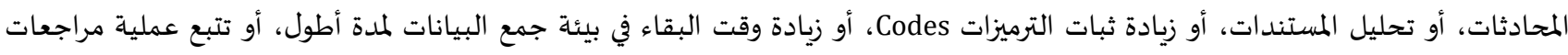

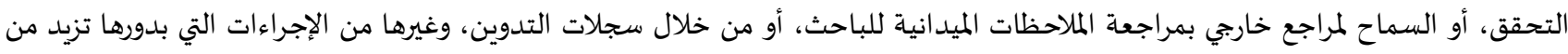

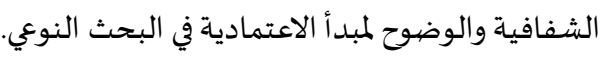


ويرى لينكولن وجوبا (Lincoln \& Guba, 1985) أنَّ هناك تداخلاً بين معايير الحكم على جودة البحث النوعي يدل على الترابط بين أجزائه؛

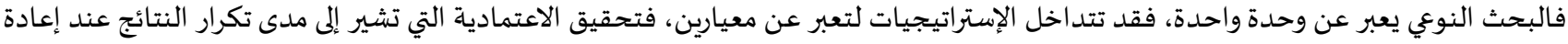

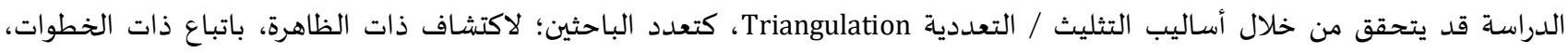
والإجراءات الدقيقة التي اتبعها الباحث الأساسي. ويتفق معاه باكستر وإيلس (Baxter \& Eyles, 1997, p. 512) في تعدد الباحثين، وتقييم الأقران، وتدقيق السجانلات، واستخدام تقنيات مهنية لتسجيل البيانات، وتقليل التفسير الوصفي الذاتي للباحث لمعاني المشاركين.

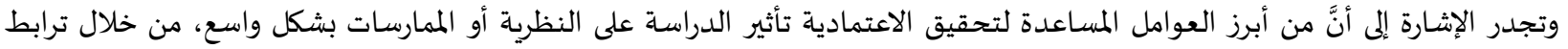

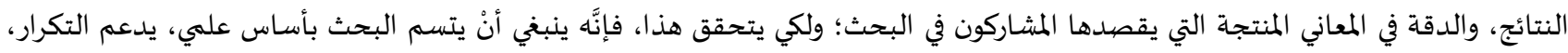

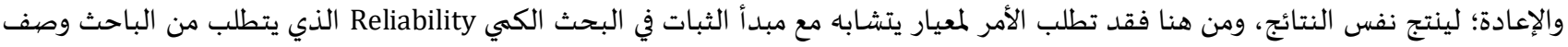

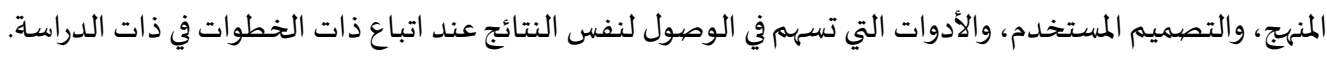

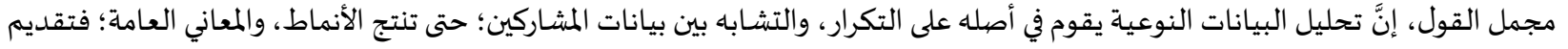

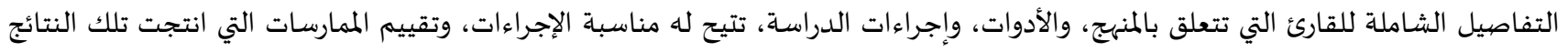

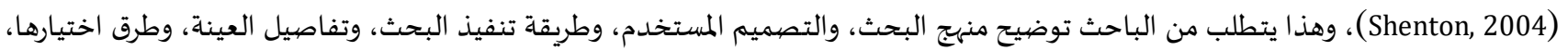

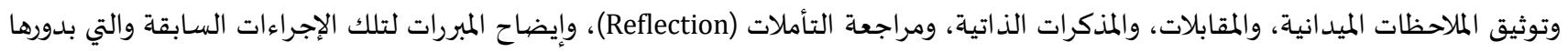
تحقق مبدأ الاعتمادية. كما أنَّ الاعتمادية في البحث النوعي تقابل الثبات في البحوث الكمية؛ فيعرفها بلور وود (Bloor \& Wood, 2006, p. 147) بأنَّا "مدى تكرار نفس

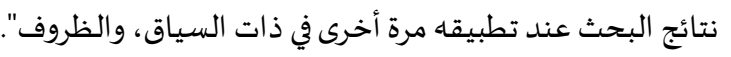

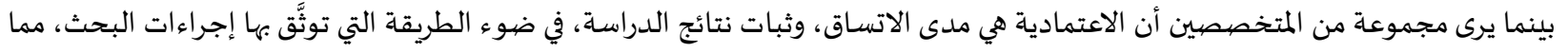

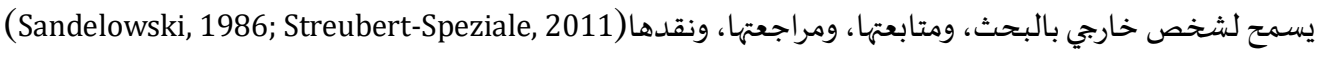

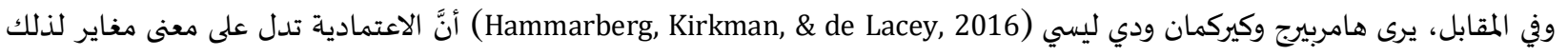

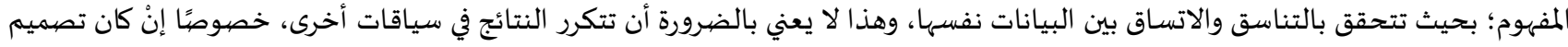

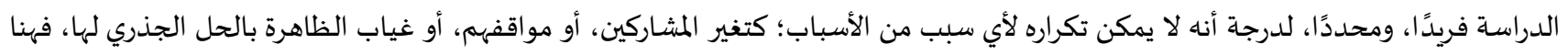

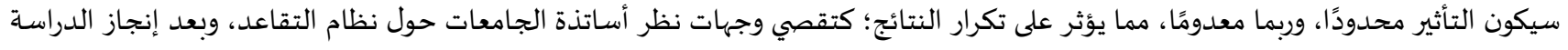

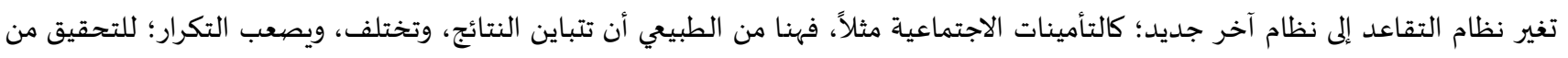

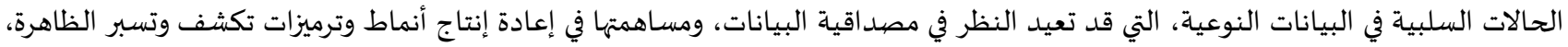

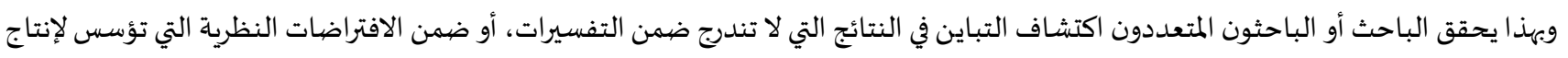
نظرية، وإعادة العمل علهيا بشكل فعَّال.

التأكيدية Confirmability

يقابل مصطلح التأكيدية - والذي يعد المتغير الرابع من متغيرات تحقيق الجودة في البحوث النوعية - مصطلح الموضوعية في البحوث الكمية

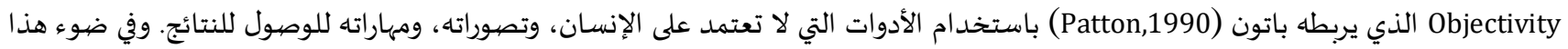

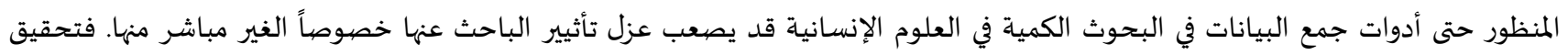

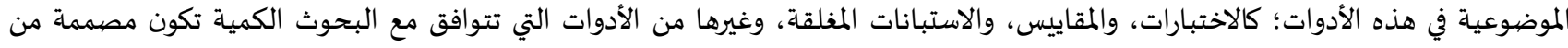

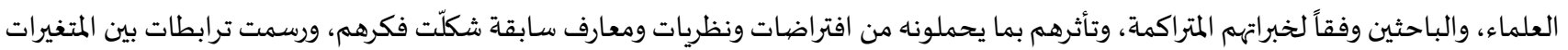

وفي المقابل؛ فإن التوكيدية في البحوث النوعية يراها باندي وباتنايك (Pandey \& Patnaik, 2014, p. 5751) بأنَّا اتخاذ الباحث خطوات

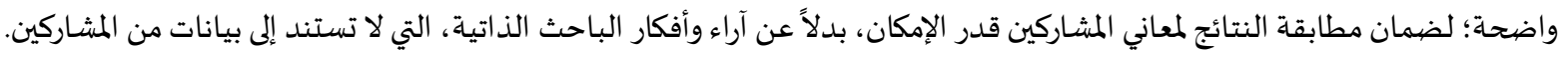

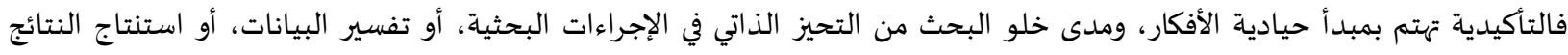

الختامية من تحليل البيانات (Ary, et. al., 2010, p. 504).

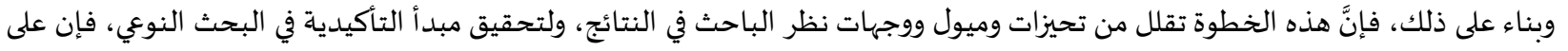

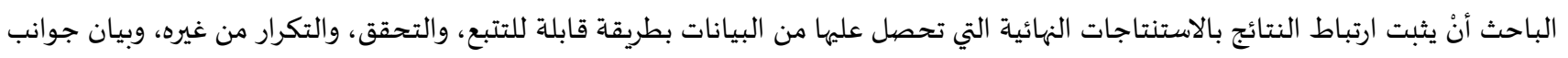
القصور التي يوصي بأخذها بعين الاعتبار كتوصيات في البحث، وإبراز الدور الذي قام بها بشكل واضح في الدراسة النوعية بمراحلها المختلفة. 
وتستخدم عدة إستراتيجيات؛ لتحقيق ذلك المعيار، وزيادة نسبة الثقة في النتائج النوعية؛ كاستخدام مصادر متعددة لجمع البيانات، وتعدد

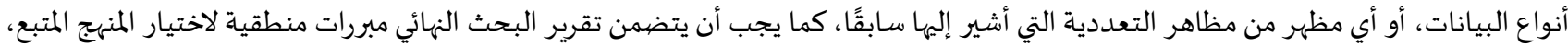
وتفضيله دون غيره من المناهج، وبيان جوانب القوة والضعف لاستخدم المنهج في تحقيق اكتشاف الظاهرة، وتبرير استخدام الأدوات، والإجراءات

التفصيلية التي اتبعها الباحث؛ للوصول لنتائج الدراسة (Shenton, 2004).

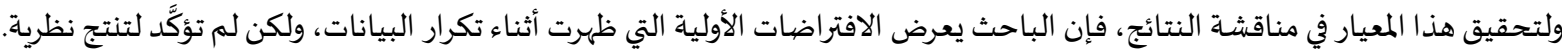

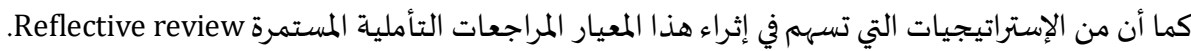

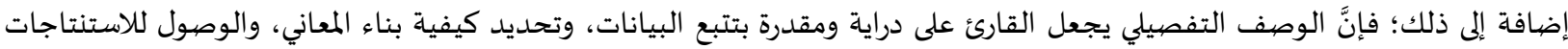

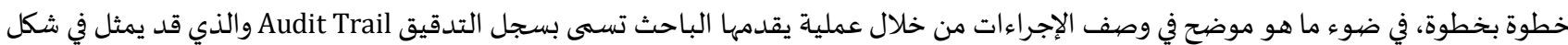
تخطيطي؛ تسهيلاً للقارئ في تتبع العملية (Shenton, 2004, p. 72) وبعد استعراض أبرز المعايير التي تحقق الجودة في البحوث النوعية؛ كالمصديداقية، والانتقالية، والتأكيدياة، والاعتمادية، والعديد من الإستراتيجيات لتحقيقها، فإنَّه من المفيد الإشارة لما اقترحاء كيتو، تشسترز، جرابك (Kitto, Chesters, \& Grbich, 2008) من معايير تُقيَّم في ضوئها

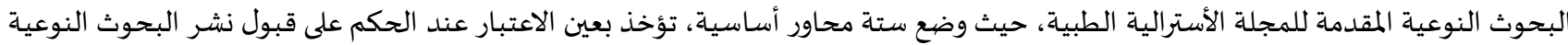

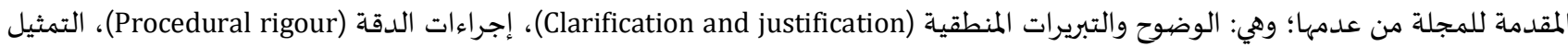
(Representativeness)، العناية بدقة التفسير (rigour Interpretative)، التأملية ودقة التقييم (Reflexivity \& evaluative rigour)، قابلية النقل (Transferability)، وعبر عن كل محور بمجموعة من الأسئلة التي تقيم في ضوئها جودة البحث النوعي من عدمها، الموضحة في الجدول رقم (r). جدول (ץ): معاييروأسئلة جودة البحوث النوعية

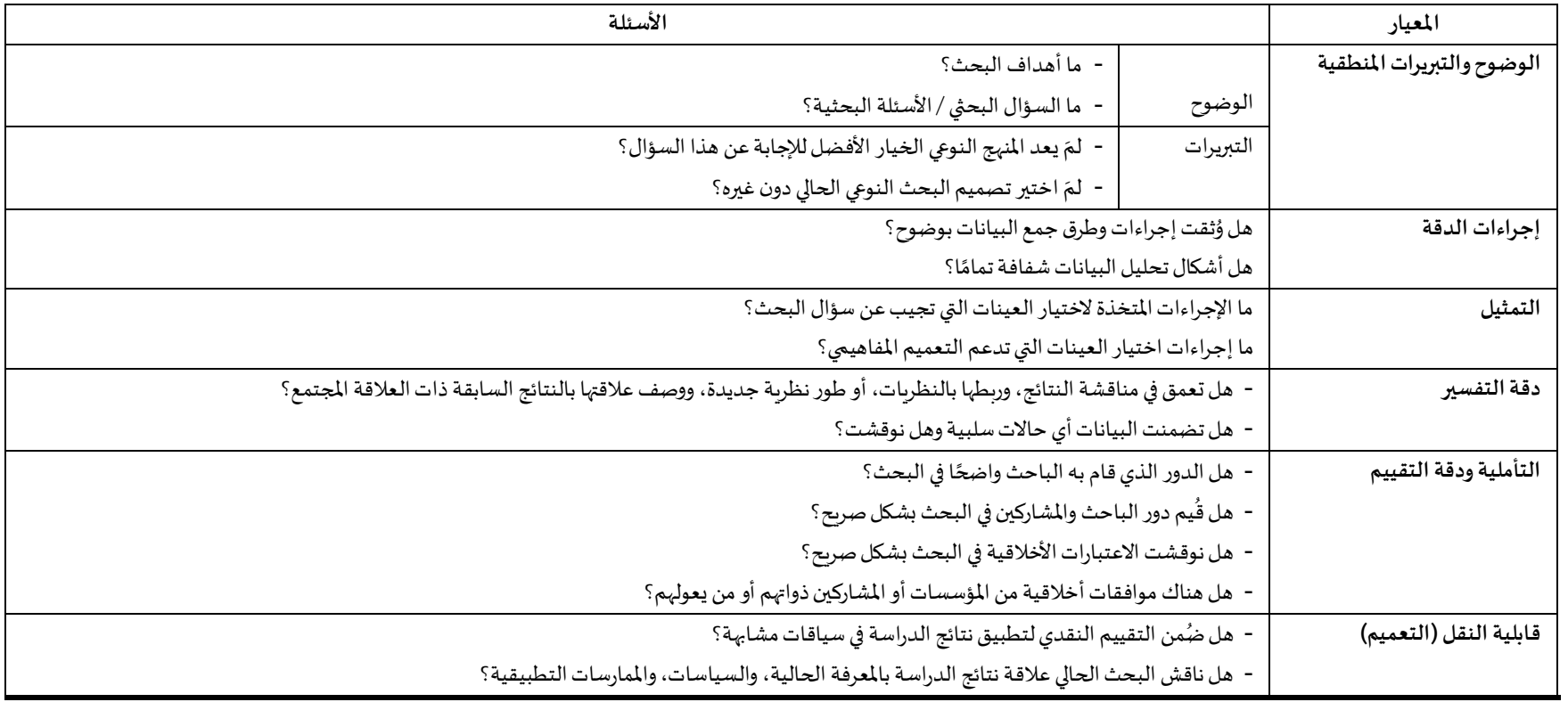

المصبدر: (Kitto, Chesters, \& Grbich, 2008,p. 244)

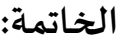

إنَّ الاهتمام المتزايد بالبحوث النوعياة، ودورها المحوري في فهم الظواهر الاجتماعية والتربوية بشكل طبيعي، ساهم في تطوير وتحديث معايير

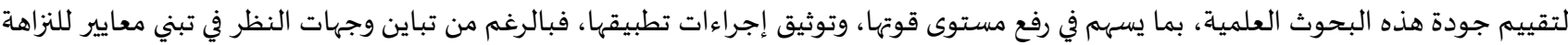

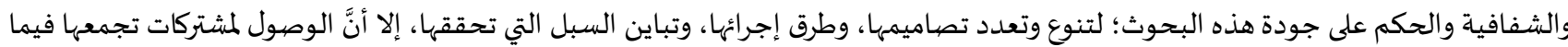
بينها ساعد في وضع معايير تقييم الجودة للبحوث النوعية، فتحقيق مبادئ الموثوقية في البحث النوعي؛ كالمصداقية، والاعتمادية، وقابلية النقل،

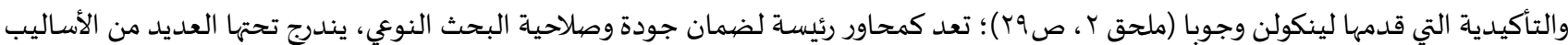
والإستراتيجيات التي تحقق في مجملها تلك المعايير العامة. 


\section{References:}

[1] Ali, A. M., \& Yusof, H. (2011). "Quality in qualitative studies: The case of validity, reliability and generalizability". Issues in Social and Environmental Accounting, 5(1-2): 25-64, https://doi.org/10.22164/isea.v5i1.59.

[2] Altheide, D. L., \& Johnson, J. M. (1994). "Criteria for assessing interpretive validity in qualitative research". In N. Denzin, \& Y. Lincoln., Handbook of qualitative research (pp. 485-499). Thousand Oaks, CA: Sage Publications.

[3] Anderson, G., \& Arsenault, N. (2005). Fundamentals of educational research. London: Falmer Press.

[4] Ary, D., Jacobs, L. C., Sorensen, C., \& Razavieh, A. (2010). Introduction to research in education. USA: Wadsworth Cengage Learning.

[5] Baxter, J., \& Eyles, J. (1997). "Evaluating qualitative research in social geography: establishing rigor in interview analysis". Transactions of the Institute of British Geographers, 22(4): 505-525, https://doi.org/10.1111/j.0020-2754.1997.00505.x.

[6] Bloor, M., \& Wood, F. (2006). Keywords in qualitative methods: A vocabulary of research concepts. London: Sage Publications.

[7] Brown, P. (2003). "Qualitative methods in environmental health research". Environmental Health Perspectives, 111(14): 1789-1798, https://doi.org/10.1289/ehp.6196.

[8] Bryman, A. (2016). Social research methods. Oxford: Oxford University Press.

[9] Campbell, D.T. (1975). "Degrees of freedom and the case study". Comparative Political Studies, 8(2): 178-193.

[10] Cohen, L., Manion, L., \& Morrison, K. (2018). Research methods in education. New York: Routledge.

[11] Creswell, J. (2007). "Qualitative in-quiry and research design: Choosing among five traditions". Thousand Oaks, CA: Sage Publications.

[12] Creswell, J. W. (2014). A concise introduction to mixed methods research. London: Sage Publications.

[13] Creswell, J. W., \& Plano Clark, V. L. (2011). Designing and conducting mixed methods research. Thousand Oaks, CA: Sage Publications.

[14] Cronbach, L. J. (1975). "Beyond the two disciplines of scientific psychology". American psychologist, 30(2): 116-127, https://doi.org/10.1037/h0076829.

[15] Crotty, M. (2015). "The foundations of social research: Meaning and perspective in the research process". London: SagePublications.

[16] Denzin, N. (1978). Sociological methods: A sourcebook. New York: McGraw Hill.

[17] Denzin, N. (1983). Interpretive Interactionism. In G. Morgan, Beyond method: Strategies for Social Research (pp. 129 146). London: Sage Publication / Beverly Hills.

[18] Denzin, N., \& Lincoln, Y. (2011). "The Sage handbook of qualitative research". London: Sage Publications.

[19] Donmoyer, R. (1990). Generalizability and the single-case study. In E. W. Eisner, \& P. A., Qualitative inquiry in education: The continuing debate (pp. 175-200). New York: Teachers College Press.

[20] Drew, C. J., Hardman, M. L., \& Hart, A. W. (1996). "Designing and conducting research: Inquiry in education and social science". London: Allyn \& Bacon.

[21] Flick, U. (1998). An introduction to qualitative research. London: Sage Publications.

[22] Flick, U. (2009). An introduction to qualitative research. London: Sage Publications.

[23] Flick, U. (2018). Designing qualitative research. London: Sage Publications.

[24] Frambach, J. M., van der Vleuten, C. P., \& Durning, S. J. (2013). "AM last page: Quality criteria in qualitative and quantitative research". Academic Medicine, 88(4): 552.

[25] Given, L. M. (2008). "The SAGE encyclopedia of qualitative research methods". Thousand Oaks, CA: Sage Publications.

[26] Guba, E. (1990).The Paradigm Dialog. London: Sage Publications.

[27] Guba, E., \& Lincoln, Y. (1994). "Do inquiry paradigms imply methodologies?" In D. Fetterman, Qualitative approaches to evaluation in education (pp. 89-115). New Yor: Praeger.

[28] Hammarberg, K., Kirkman, M., \& de Lacey, S. (2016). "Qualitative research methods: when to use them and how to judge them". Human reproduction, 31(3): 498-501, https://doi.org/10.1093/humrep/dev334.

[29] Hammersley, M. (2005). "Assessing quality in qualitative research". ESRC TLRP seminar series: Quality in educational research, 103-113. 
[30] Hammersley, Martyn (2013). "What is Qualitative Research? What Is? Research Methods". London: Continuum/Bloomsbury.

[31] Harvey, L.; MacDonald, M. (1993). Doing Sociology: A Practical Introduction. London: Macmillan International Higher Education

[32] Henn, M., Weinstein, M., \& Foard, N. (2005). A short introduction to social research. London: Sage Publications.

[33] Kitto, S. C., Chesters, J., \& Grbich, C. (2008). "Quality in qualitative research: criteria for authors and assessors in the submission and assessment of qualitative research articles". Medical Journal of Australia, 188(4): 243-246.

[34] Kneller, G. F. (1971). Introduction to Philosophy of Education. Hoboken, N.J: John Wiley \& Sons,Inc.

[35] Köckeis-Stangl, E. (1980). Methoden der Sozialisationsforschung. In K. Hurrelmann, \& D. Ulich, Handbuch der Sozialisationsforschung (pp. 321-369).

[36] Krefting, L. (1991). "Rigor in qualitative research: The assessment of trustworthiness". The American Journal of Occupational Therapy, 45(3): 214-222, https://doi.org/10.5014/ajot.45.3.214.

[37] Lichtman, M. (2013). "Qualitative research in education: A user's guide: A user's guide". London: Sage Publications.

[38] Lincoln, Y. S., \& Guba, E. A. (1985). Naturalistic inquiry. Beverly Hills, CA: Sage Publications.

[39] Mackey, A., \& Gass, S. M. (2016). Second language research: Methodology and design. New York: Routledge.

[40] Marczyk, G., DeMatteo, D., \& Festinger, D. (2005). Essentials of research design and methodology. John Wiley \& Sons Inc. Hoboken, N.J: John Wiley \& Sons Inc.

[41] Maxwell, J. (1992). "Understanding and validity in qualitative research". Harvard educational review, 62(3): 279-301, https://doi.org/10.17763/haer.62.3.8323320856251826.

[42] Merriam, S. (2009). Qualitative research: A guide to design and implementation. San Francisco, CA: Jossey Bass.

[43] Newman, I., \& Benz, C. R. (1998). "Qualitative-quantitative research methodology: Exploring the interactive continuum". Carbondale: University of Illinois Press.

[44] Padgett, D. K. (2011). "Qualitative and mixed methods in public health". London: Sage Publications.

[45] Pandey, S. C., \& Patnaik, S. (2014). "Establishing reliability and validity in qualitative inquiry: A critical examination". Jharkhand journal of development and management studies, 12(1): 5743-5753.

[46] Parkinson, G., \& Drislane, R. (2011). "Qualitative research. In Online dictionary of the social sciences". Retrieved from http://bitbucket.icaap.org/dict.pl

[47] Patton, M. Q. (1990). Qualitative evaluation and research methods. Newbury: Sage Publications.

[48] Patton, M. Q. (1999). "Enhancing the quality and credibility of qualitative analysis". Health services research, 34(5): 1189-1209.

[49] Polkinghorne, D. E. (2007). "Validity issues in narrative research". Qualitative inquiry, 13(4): 471-486, https://doi.org/10.1177/1077800406297670.

[50] Pring, R. (2015). Philosophy of educational research. London: Sage Publications.

[51] Reid, A. \& Cough, S. (2000). "Guidelines for reporting and evaluating qualitative research: what are the alternative?" Environmental Education Research, 6(1): 59-91, https://doi.org/10.1080/135046200110494.

[52] Ritchie, J., Lewis, J., Nicholls, C. M., \& Ormston, R. (2014). "Qualitative research practice: A guide for social science students and researchers". London: Sage Publications.

[53] Sandelowski, M. (1986). "The problem of rigor in qualitative research". Advances in Nursing Science, 8(3): 27-37, https://doi.org/10.1097/00012272-198604000-00005.

[54] Sarantakos, S. (2012). Social research. New York: Macmillan International Higher Education.

[55] Schwandt, T. (2000). "Three epistemological stances for qualitative inquiry: Interpretation, hermeneutics, and social construction". In N. K. Denzin., \& Y. S. Lincoln., Handbook of qualitative research (pp. 189-213). Thousand Oaks, CA: Sage Publications.

[56] Seale, C. (1999). "Quality in qualitative research". Qualitative inquiry, 5(4), 465-478.

[57] Shenton, A. K. (2004). "Strategies for ensuring trustworthiness in qualitative research projects". Education for Information, 22(2): 63-75, https://doi.org/10.3233/efi-2004-22201.

[58] Silverman, D. (2013). Doing qualitative research: A practical handbook. London: Sage Publications.

[59] Smith, K. (1984). "The problem of criteria for judging interpretive inquiry". Educational Evaluation and Policy Analysis, 6(4): 379-391, https://doi.org/10.3102/01623737006004379. 
[60] Strauss, A., \& Corbin, J. (1998). "Basics of qualitative research: Tech-niques and procedures for devel-oping grounded theory". London: Sage Publications.

[61] Streubert-Speziale, H. J. (2011). "Designing data generation and management strategies". In S. H. S., H. J. Streubert, \& D. R. Carpenter, Qualitative research in nursing: Advancing the humanistic imperative (pp. 33-55). New York: Lippincott Williams \& Wilkins.

[62] Volmerg, U. (1983). "Validität im interpretativen paradigma. Dargestellt an derKonstruktion qualitativer Erhebungsverfahren". In P. Zedler, \& H. Moser., Aspekte qualitativer Sozialforschung (pp. 124-143). Opladen: Leske and Budrich.

[63] Wagner, C., Kawulich, B., \& Garner, M. (2012). "Doing social research: A global context". London: McGraw-Hill Higher Education.

[64] Wellington, J. (2015). "Educational research: Contemporary issues and practical approaches". London: Bloomsbury Publishing.

[65] Willis, J. W., Jost, M., \& Nilakanta, R. (2007). "Foundations of qualitative research: Interpretive and critical approaches". London: Sage Publications. 
المجلة الدولية للدراسـات التربوية والنفسية

International Journal of Educational \& Psychological Studies (EPS)

Journal Homepage: https://www.refaad.com/views/EPSR/Home.aspx

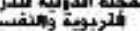

www.refaad.com

ISSN: 2520-4149 (Online) 2520-4130 (Print)

\title{
Criteria to evaluate the quality of qualitative research in social science
}

\author{
Mohammed Abdullah A. Alzahrani
}

Faculty of Education, Department of Curricula and Instructions, University of Bisha, KSA

University of Exeter, Graduate of School of Education, United Kingdom alahmadim2010@gmail.com

\author{
Received : 23/4/2020 Revised : 4/5/2020 Accepted : 14/5/2020 DOI : https://doi.org/10.31559/EPS2020.8.3.4
}

Abstract: The current research aims to introduce criteria for evaluating qualitative research in social sciences research. The qualitative research was established in light of interpretivism viewpoint which has a different view from positivism or post-positivism worldviews. Both latter viewpoints believe that social phenomena have a degree of stability and discovering the rules and correlations between variables can lead to understanding the social phenomena. Based on that view, the quality of quantitative research is carried out through validity and reliability procedures. On the other hand, qualitative research supposed that meaning is forming from participants themselves. The constructivist view can adopt new quality criteria for qualitative research. Therefore, this research attempts to shed light on the quality standards for qualitative research in a simple form to assist researchers while carrying out qualitative research in social research.

Keywords: Qualitative Research; Trustworthiness; Social Science; Evaluate. 


\section{ملحق رقم (1)}

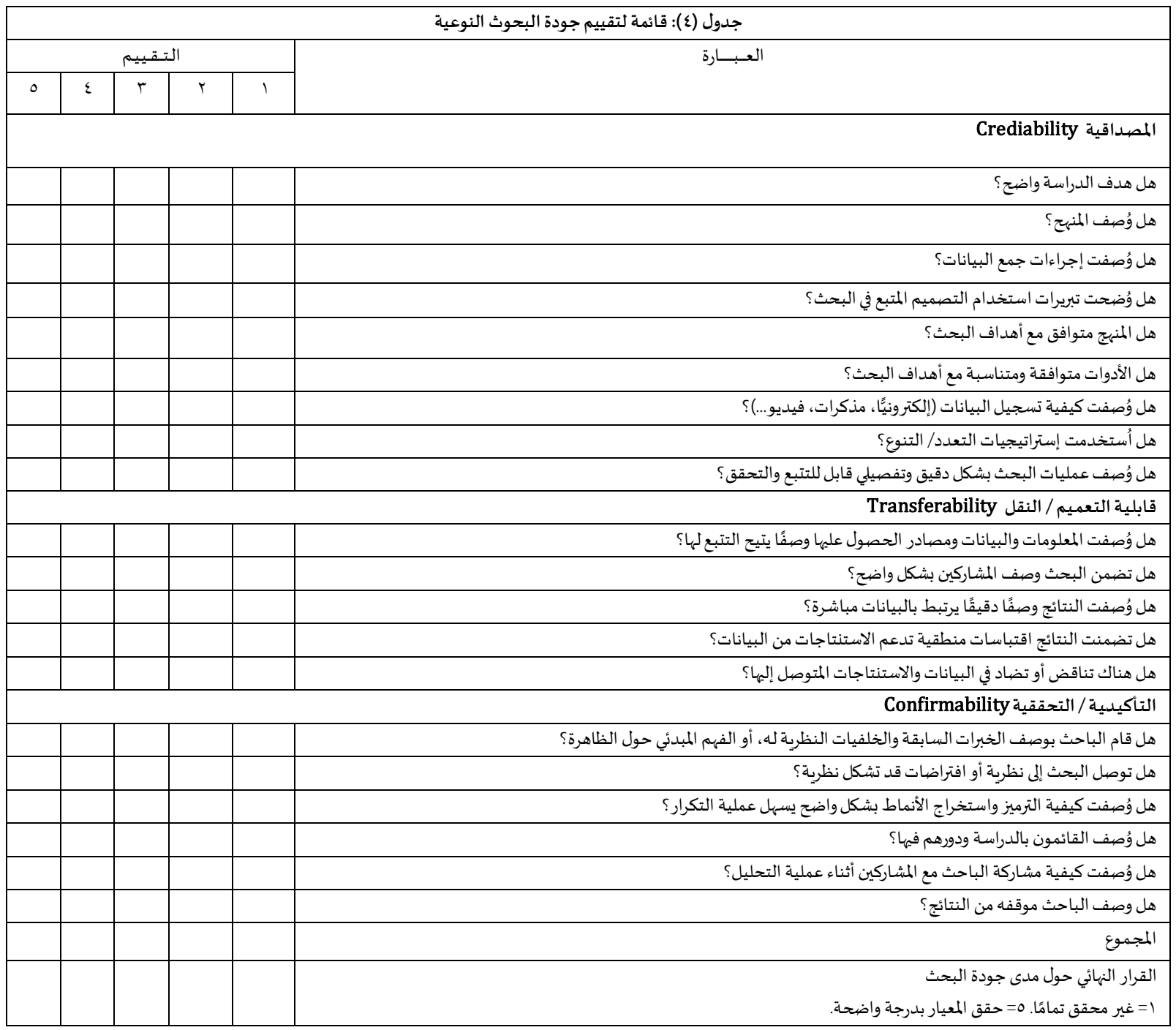

\section{ملحق رقم (r)}

مصطلحات في بحوث النوعية

\begin{tabular}{|c|c|}
\hline المصطلح & 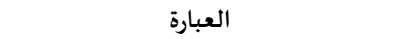 \\
\hline 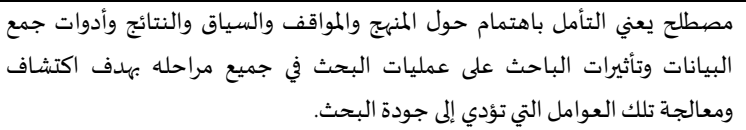 & التأملية / الانعكاسية Reflexivity \\
\hline مجموعة من المعايير التي تقيم جودة البحوث النوعية. & الموثوقية Trustworthiness \\
\hline 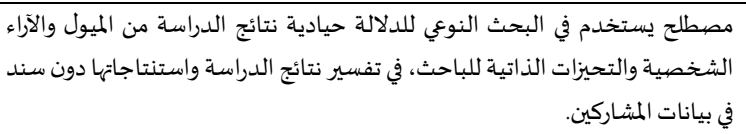 & التأكيدية / إمكانية التثبّت Confirmability \\
\hline 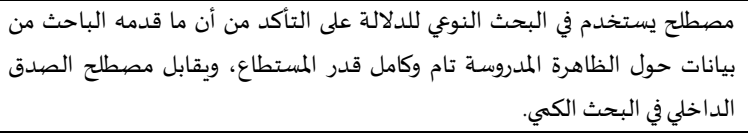 & المصيداقية Credibility \\
\hline مصابها مصلح يستخدم في البحث النوعي للدلالة على إمكانية نقل نتائج الدراسـة من سياق القدرة على نقل النتائج والاستفادة من في الاسترشاد في سياقات & قابلية النقل / التعميم \\
\hline مصنونه بها. يهدف إلى التأكد من التفسيرات المنتجة من البيانات وارتباطها بالمشاركين وما & $\begin{array}{r}\text { الاعتمادية / اتساق النتائج } \\
\text { Dependability }\end{array}$ \\
\hline تعدد المصادر التي تجمع منها البيانات، والأساليب، والنظريات المفسرة للنتائج، & Triangulation التثليث \\
\hline
\end{tabular}




\begin{tabular}{|c|c|}
\hline والباحثين، والبيئات والأزمنة التي تجمع بها البيانات. & \\
\hline 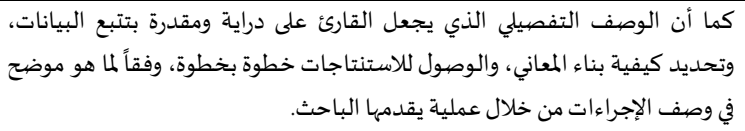 & سجل التدقيق \\
\hline لمصيطاح قدمه جيرتز & الوصف المستفيض / المكثف \\
\hline
\end{tabular}

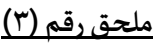

معاير الجودة في البحوث الكمية والنوعية

\begin{tabular}{|c|c|c|c|c|}
\hline طرق تحقيق جودة البحث & معاييرجودة البحث النوعي & مظاهر المقارنة & معاير الجودة بالبحث الكهي & طرق تحقيق جودة البحث الكمي \\
\hline 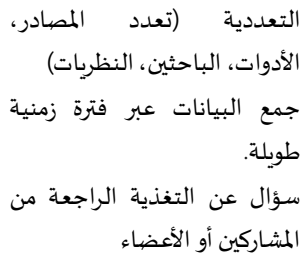 & ولمصيداقية Credibility & $\begin{array}{r}\text { صحة القيم } \\
\text { Truth Value }\end{array}$ & 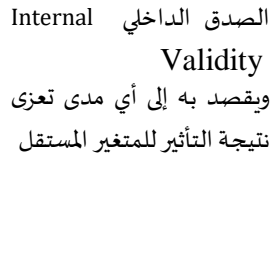 & 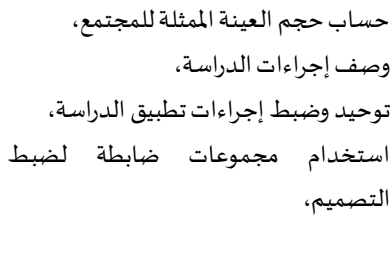 \\
\hline 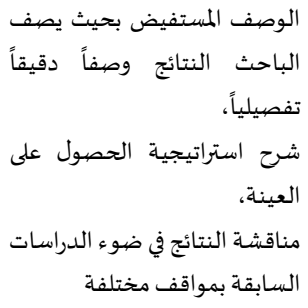 & $\begin{array}{r}\text { أوانتقالية (القابلية للتحويل) } \\
\text { Transferability } \\
\text { أوضاع مختلفة إمكانية نقل النتائج أو تطبيقها في } \\
\text { في }\end{array}$ & التطبيق Applicability & 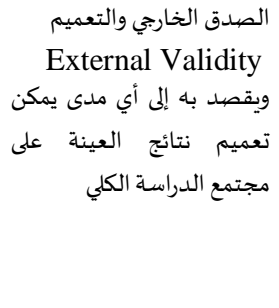 & 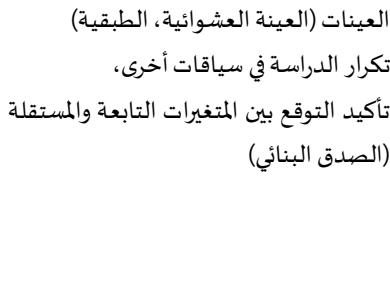 \\
\hline 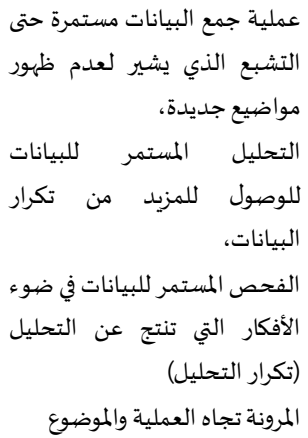 & 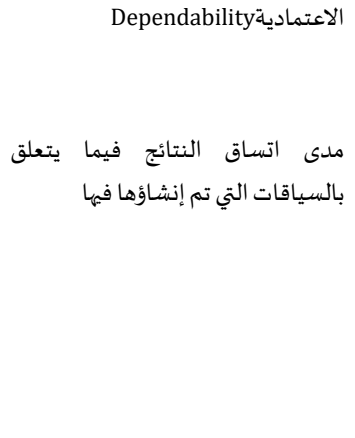 & $\begin{array}{r}\text { Consistency اتساق وترابط الأدلة } \\
\text { of Evidence }\end{array}$ & 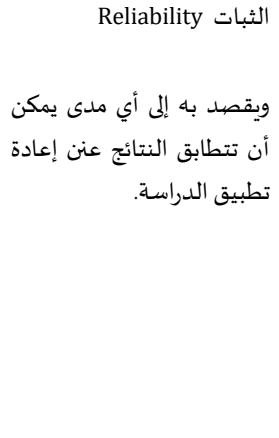 & 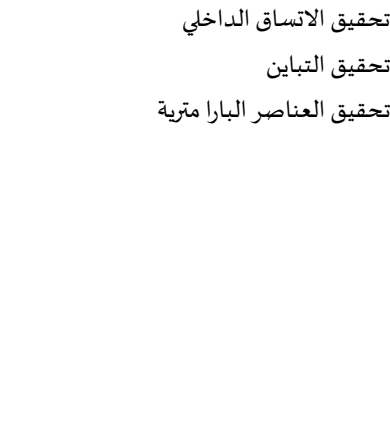 \\
\hline 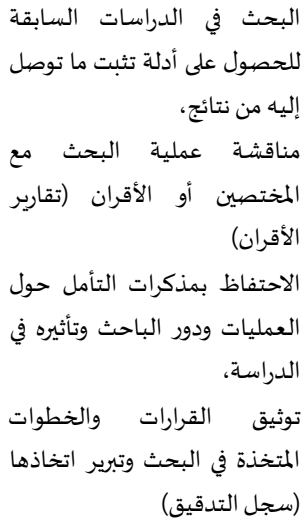 & 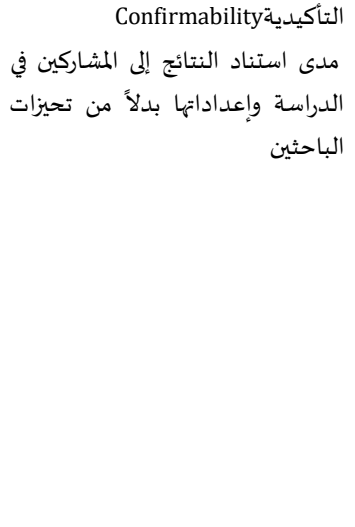 & موضوعية وحيادية الأدلة & 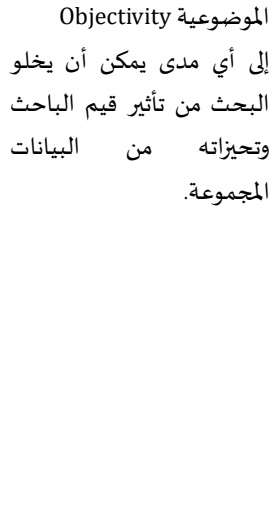 & 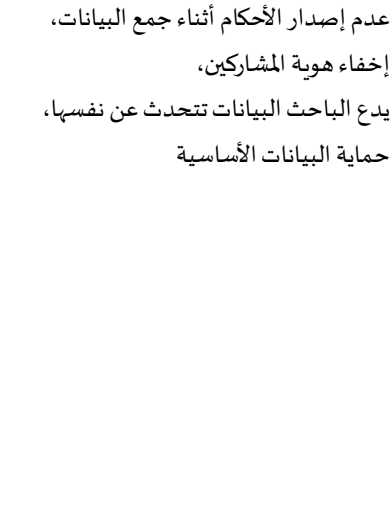 \\
\hline
\end{tabular}

(Frambach, van der Vleuten, \& Durning, 2013, p. 552) 